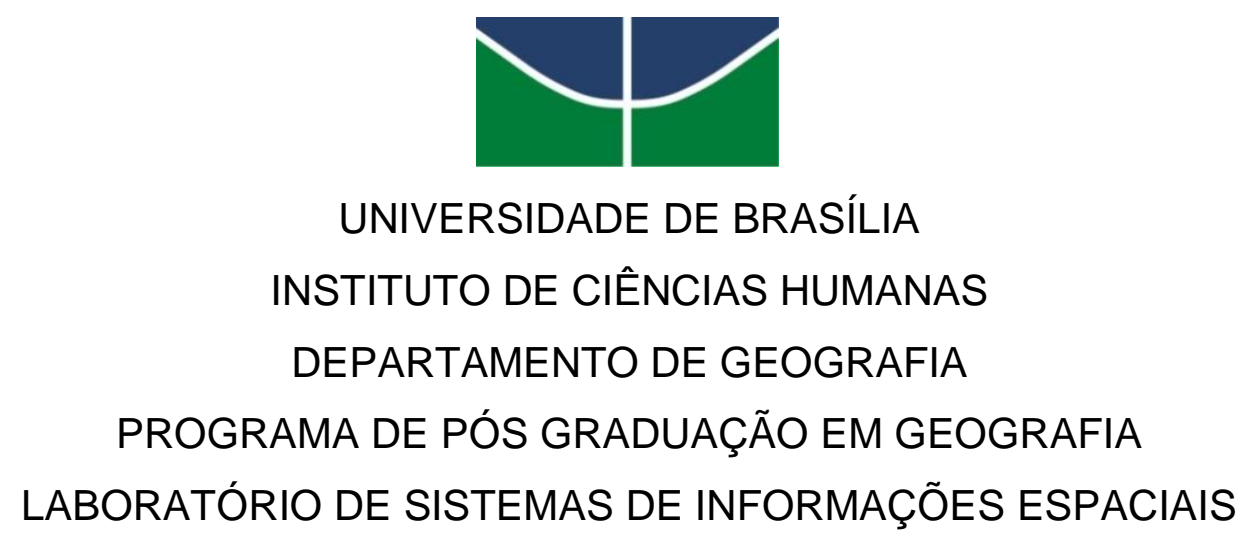

UTILIZAÇÃO DE MODELAGEM MATEMÁTICA PARA IDENTIFICAÇÃO DE ÁREAS SUSCETÍVEIS A ESCORREGAMENTOS NA SERRA DAS ARARAS - RJ

Argélica Saiaka Luiz

Orientador: Prof. Dr. Renato Fontes Guimarães

Coorientador: Prof. Dr. Roberto Arnaldo Trancoso Gomes

Dissertação de Mestrado

Brasília, dezembro de 2015 


\author{
UNIVERSIDADE DE BRASÍLIA \\ INSTITUTO DE CIÊNCIAS HUMANAS \\ DEPARTAMENTO DE GEOGRAFIA \\ MESTRADO EM GEOGRAFIA \\ PROGRAMA DE PÓS GRADUAÇÃO EM GEOGRAFIA \\ LABORATÓRIO DE SISTEMAS DE INFORMAÇÕES ESPACIAIS
}

\title{
UTILIZAÇÃO DE MODELAGEM MATEMÁTICA PARA IDENTIFICAÇÃO DE ÁREAS SUSCETÍVEIS A ESCORREGAMENTOS NA SERRA DAS ARARAS (RJ)
}

\author{
Argélica Saiaka Luiz
}

Dissertação de Mestrado submetida ao Departamento de Geografia da Universidade de Brasília, como parte dos requisitos necessários para obtenção do Grau de Mestre em Geografia, área de concentração Gestão Ambiental e Territorial.

Prof. Dr. Renato Fontes Guimarães

Universidade de Brasília - Departamento de Geografia

Orientador

Prof. Dr. Roberto Arnaldo Trancoso Gomes

Universidade de Brasília - Departamento de Geografia

Coorientador

Profa. Dra. Nóris Costa Diniz

Universidade de Brasília - Departamento de Geologia

Examinador Externo

Prof. Dr. Éder de Souza Martins

EMBRAPA/DF

Examinador Externo

Prof. Dr. Osmar Abílio de Carvalho Júnior

Universidade de Brasília - Departamento de Geografia

Examinador Interno - suplente 


\section{LUIZ, ARGÉLICA SAIAKA}

Utilização de Modelagem Matemática para Identificação de Áreas Suscetíveis a Escorregamentos na Serra das Araras (RJ), 52 p. (UnB-IH-GEA-LSIE, Mestrado, 2015).

Dissertação de Mestrado - Universidade de Brasília. Departamento de Geografia.

1. Escorregamentos

3.SHALSTAB

5. MDS

I. UnB-IH-PPGEA-LSIE
2.Retroanálise

4. MDT

II. Título (série) 


\section{AGRADECIMENTOS}

Quero agradecer aqueles que sempre acreditaram na realização desse trabalho, em especial

A minha mãe e meu pai, sem eles nada disso seria ao menos possível, agradeço o apoio e a dedicação que sempre tiveram.

Ao Anesmar, pela ajuda direta na construção do trabalho, pela preocupação e companheirismo sempre.

Aos amigos do Lsie, Vitor Paiva, Vitor Hugo, Rebecca Albuquerque e Pedro Coutinho, que acompanharam todo o processo de desenvolvimento, e que sempre contribuíram mesmo que com detalhes.

A Nathalia Silva Costa, pela amizade, pelo apoio, pela ajuda mesmo estando desenvolvendo seu próprio trabalho.

A Verônica Ramos, pelas tardes em que me ajudou e esclareceu várias dúvidas, além das conversas e conselhos, que por fim se tornou uma amiga para mim.

Ao Professor Dr. Renato Fontes Guimarães, pelo incentivo e confiança para realização dessa empreitada, apesar dos obstáculos na construção da metodologia que foi complicada e longa além da indiscutível amizade e compreensão.

Ao Professor Dr. Roberto Arnaldo Trancoso Gomes, pela liberdade, amizade e ajuda principalmente nos últimos dias antes da entrega do trabalho mesmo estando longe.

Ao Professor Dr. Osmar Abílio de Carvalho Junior pela dedicação e apoio, sem ele o trabalho não teria se concretizado e por sua amizade e paciência. 
Os escorregamentos são desastres naturais frequentes e estão fortemente ligados a topografia. O clima é um fator determinante no contexto desse tipo de fenômeno. O tipo de relevo e a quantidade de precipitação são fatores fundamentais para desencadear esse tipo de movimento de massa. As metodologias ligadas à predição de escorregamentos,como a retroanálise, ajudam no diagnóstico de áreas mais propícias e possibilitam a implantação de manobras mitigadoras para minimizar os efeitos desse tipo de desastre natural. Dentre os métodos mais usados para a previsão de escorregamentos encontra-se o SHALSTAB, o qual resulta da combinação de um modelo de instabilidade de encosta e um modelo hidrológico e determina a razão entre a transmissividade e a quantidade de chuva necessária para a deflagração de escorregamentos. Este trabalho tem por objetivo identificar as áreas susceptíveis a escorregamentos translacionais, em um fragmento da Serra das Araras, município de Paracambi - RJ. As etapas para aplicação do modelo SHALSTAB para previsão de áreas com predisposição a escorregamentos foram: a) confecção de MDS a partir de fotografias aéreas, B) confecção do MDT e C) aplicação do modelo SHALSTAB. O método aplicado atingiu o objetivo proposto e demonstrou que sua aplicação é fácil e viável e pode ser uma ferramenta de grande auxilio para o planejamento de desastres naturais em escala local e regional.

Palavras- chave: Escorregamentos, Retroanálise, SHALSTAB, MDS, MDT 


\section{ABSTRACT}

The landslides are frequent natural disasters and are strongly linked to topography. The weather is a determining factor in the context of this kind of phenomenon. The relief type and amount of precipitation are key players to trigger this type of mass movement. Methodologies related to the prediction of landslides, such as back analysis, help in diagnosing more favorable areas and enable the implementation of mitigating maneuvers to minimize the effects of this natural disaster. Among the methods most frequently used for this kind of prediction in the SHALSTAB, which is the result of a joint between the slope instability model and hydrological models that determine the ratio of the transmissivity and the amount of rainfall required for the landslides deflagration. This study objective is to identify areas susceptible to translational landslides, in a fragment of the Serra das Araras in the Paracambi - RJ county. The steps for implementation of SHALSTAB model to predict the areas prone to landslides were: a) making DSM from aerial photographs, b) making the DTM and c) applying SHALSTAB. Model the applied method achieved its objectives and demonstrated that its application is easy and viable, that can be a great aid tool for the planning of natural disasters and local and regional scale.

Key words: Landslide, back analysis, SHALSTAB, DSM, DTM. 


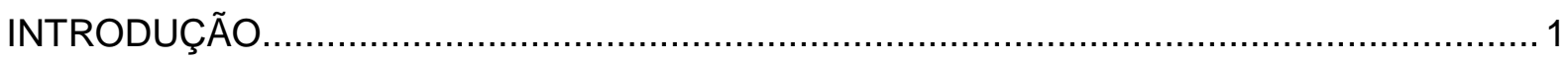

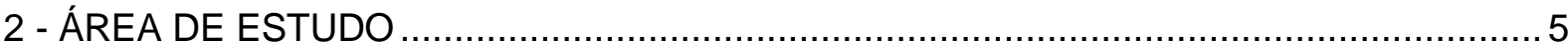

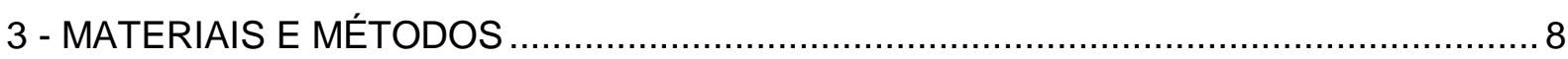

3.1 - Elaboração do Modelo Digital de Superfície (MDS) ……………………….......

3.2 - Confecção do Modelo Digital de Terreno (MDT) …………………………....... 11

3.3 - Obtenção dos parâmetros morfométricos ......................................................... 16

3.4 - Simulações a partir do Modelo SHALSTAB ……………………………........ 17

3.5 - Mapeamento de Cicatrizes .......................................................................... 19

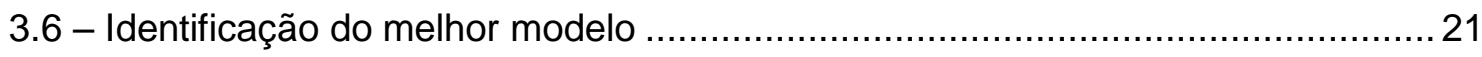

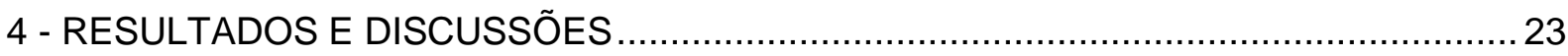

4.1 - Resultados dos MDT, MDS e de seus Atributos de Terreno ………………….....23

4.2 - Resultados das simulações com o SHALSTAB para o MDS ………………........2

4.3 - Resultados das simulações com o SHALSTAB para o MDT ..................................... 30

4.4 - Resultados da melhor simulação SHALSTAB usando o MDT ...............................34

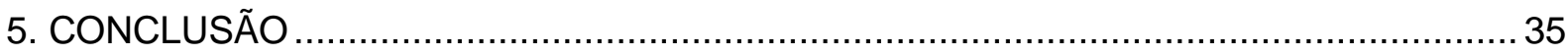

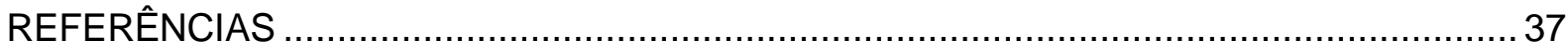




\section{LISTA DE FIGURAS}

Figura 1 - Figura esquemática da representação dos pontos de elevação extraídos do modelo digital de terreno (linha preta e pontos vermelhos) e do modelo digital de superfície (linha azul e pontos amarelos) .................................................... 3

Figura 2 - Mapa de localização da área de estudo.......................................................... 5

Figura 3 - Fotografias da área de estudo demonstrando cicatrizes de alguns movimentos

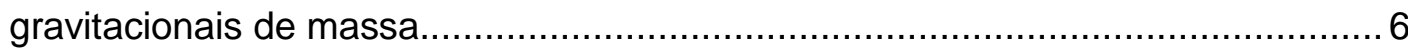

Figura 4 -Fluxograma da metodologia aplicada no trabalho.

Figura 5 - Exemplo dos pares estereoscópicos utilizados para a geração do MDS no programa Inpho.

Figura 6 - Modelo estereoscópico em que, as fotos e as curvas de nível estão sobrepostas ao MDS para seu tratamento e posterior geração do MDT.

Figura 7 - Superfície topográfica em 3D e as linhas de apoio utilizadas para suavização... 12

Figura 8 - (a) Perfil topográfico com nuvem de pontos antes da interpolação e (b) perfil topográfico com os pontos interpolados utilizando a linha de apoio.

Figura 9 - Edições do MDS para obtenção do MDT (a) relevo sombreado e as linhas de drenagens e (b) relevo sombreado e as curvas de nível.

Figura 10 - Perfis topográficos de antes (a) e depois (b) da correção de lagos. 15

Figura 11 - Exibição da nuvem de pontos do MDS e MDT (A-B); exibição do relevo sombreado do MDS e MDT (C-D), exibição da superfície hipsométrica e relevo sombreado do MDS e MDT $(E-F)$.................................................. 16

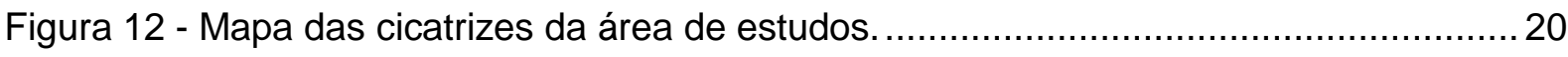

Figura 13 - (A) Mapa altimétrico a partir do MDS; (B) Mapa altimétrico a partir do MDT; (C) Histograma de frequência dos valores de altitude do MDS; (D) Histograma de frequência dos valores de altitude do MDT.

Figura 14 - (A) Mapa de declividade gerado do MDS; (B) Mapa de declividade gerado do MDT; (C) Histograma de frequência do mapa de declividade do MDS; (D) Histograma de frequência do mapa de declividade do MDT

Figura 15 - (A) Mapa de área de contribuição gerado a partir do MDS; (B) Mapa de área de contribuição gerado a partir do MDT; (C) Histograma de frequência do mapa de área de contribuição do MDS; (D) Histograma de frequência do mapa de área de contribuição do MDT.

Figura 16 - Simulações do SHALSTAB utilizando os dados do MDS: (a) simulação 1 $\left(\mathrm{C} / \mathrm{z}=2, \rho_{s} / \rho_{w}=1,5\right.$ e $\left.\varphi=30\right),(\mathrm{b})$ simulação $2\left(\mathrm{C} / \mathrm{z}=4, \rho_{s} / \rho_{w}=1,5\right.$ e $\left.\varphi=30\right),(\mathrm{c})$ 
simulação $3\left(\mathrm{C} / \mathrm{z}=2, \rho_{s} / \rho_{w}=2\right.$ e $\left.\varphi=30\right)$ e $(\mathrm{d})$ simulação $4\left(\mathrm{C} / \mathrm{z}=4, \rho_{s} / \rho_{w}=2\right.$ e $\varphi=30)$..

Figura 17 - Simulações do SHALSTAB utilizando os dados do MDS: (a) simulação 5), $\left(\mathrm{C} / \mathrm{z}=0, \rho_{s} / \rho_{w}=1,5\right.$ e $\left.\varphi=45\right)$ (b) simulação $6\left(\mathrm{C} / \mathrm{z}=2, \rho_{s} / \rho_{w}=1,5\right.$ e $\left.\varphi=45\right),(\mathrm{c})$ simulação $7\left(\mathrm{C} / \mathrm{z}=4, \rho_{s} / \rho_{w}=1,5\right.$ e $\left.\varphi=45\right)$, (d) simulação 8, $\left(\mathrm{C} / \mathrm{z}=0, \rho_{s} / \rho_{w}=2 \mathrm{e}\right.$ $\varphi=45)(\mathrm{e})$ simulação $9\left(\mathrm{C} / \mathrm{z}=2, \rho_{s} / \rho_{w}=2\right.$ e $\left.\varphi=45\right)$, (f) simulação $10,(\mathrm{C} / \mathrm{z}=4$, $\rho_{s} / \rho_{w}=2$ e $\left.\varphi=45\right)$.

Figura 18 - Simulações do SHALSTAB utilizando os dados do MDT: (a) simulação 1 $\left(\mathrm{C} / \mathrm{z}=2, \rho_{s} / \rho_{w}=1,5\right.$ e $\left.\varphi=30\right)$, (b)simulação $2\left(\mathrm{C} / \mathrm{z}=4, \rho_{s} / \rho_{w}=1,5\right.$ e $\left.\varphi=30\right)$, (c) simulação $3\left(\mathrm{C} / \mathrm{z}=2, \rho_{s} / \rho_{w}=2\right.$ e $\left.\varphi=30\right)$ e $(\mathrm{d})$ simulação $4\left(\mathrm{C} / \mathrm{z}=4, \rho_{s} / \rho_{w}=2\right.$ e $\varphi=30)$.

Figura 19 - Simulações do SHALSTAB utilizando os dados do MDT: (a) simulação 5), $\left(\mathrm{C} / \mathrm{z}=0, \rho_{s} / \rho_{w}=1,5\right.$ e $\left.\varphi=45\right)(\mathrm{b})$ simulação $6\left(\mathrm{C} / \mathrm{z}=2, \rho_{s} / \rho_{w}=1,5\right.$ e $\left.\varphi=45\right)$, (c) simulação $7\left(\mathrm{C} / \mathrm{z}=4, \rho_{s} / \rho_{w}=1,5\right.$ e $\left.\varphi=45\right)$, (d) simulação 8, $\left(\mathrm{C} / \mathrm{z}=0, \rho_{s} / \rho_{w}=2 \mathrm{e}\right.$ $\varphi=45)(\mathrm{e})$ simulação $9\left(\mathrm{C} / \mathrm{z}=2, \rho_{s} / \rho_{w}=2\right.$ e $\left.\varphi=45\right)$, (f) simulação $10,(\mathrm{C} / \mathrm{z}=4$, $\rho_{s} / \rho_{w}=2$ e $\left.\varphi=45\right)$. 


\section{LISTA DE TABELAS}

Tabela 1 - Parâmetros utilizados na modelagem do SHALSTAB com base no MDS e MDT.

Tabela 2 - O número de pixel dentro das cicatrizes relativas às classes do modelo SHALSTAB a partir dos dados MDS, considerando diferentes parâmetros reológicos.

Tabela 3 - A porcentagem de área dentro das cicatrizes relativas às classes do modelo SHALSTAB a partir dos dados MDS, considerando diferentes parâmetros reológicos.

Tabela 4 - O número de pixel das classes do modelo SHALSTAB usando os dados do MDT dentro das cicatrizes, considerando os diferentes parâmetros reológicos.

Tabela 5 - O número de pixel das classes do modelo SHALSTAB usando os dados do MDT dentro das cicatrizes, considerando os diferentes parâmetros reológicos. 30

Tabela 6 - Valores de média e mediana dentro das cicatrizes. 31

Tabela 7 - Ordenamento do ranque das simulações do SHALSTAB considerando diferentes valores para os parâmetros reológicos. 


\section{INTRODUÇÃO}

O movimento gravitacional de massa é um processo natural de evolução da paisagem e do relevo, tendo uma abrangência contínua na escala espaço-temporal (BLIJENBERG, 1998). Diversas classificações de movimentos gravitacionais de massa foram propostas considerando a diversidade dos materiais e os processos condicionantes. Esses movimentos podem ser classificados como quedas de blocos, subsidências, escorregamentos (translacionais ou rotacionais) escoamentos, rastejos e corridas de massa (GUIMARÃES et al., 2008). Os escorregamentos translacionais são os movimentos que mais ocorrem na paisagem (BORGA et al., 1998). Conforme Selby (1993), os escorregamentos rotacionais e translacionais se diferenciam, principalmente, pela forma do plano de ruptura e espessura. $\mathrm{O}$ escorregamento rotacional possui uma forma curva com vários planos de ruptura, contendo, normalmente, espessura de material e tempo de duração maior do que o escorregamento translacional. $O$ escorregamento translacional possui um plano de ruptura bem definido, ocorre predominantemente em ruptura no contato solo e rocha (SELBY, 1993, GERSCOVICH, 2012). Ambos os escorregamentos apresentam uma grande capacidade de destruição (SELBY, 1993; GUIMARÃES et al., 2008). Além disso, os escorregamentos desencadeiam as corridas de massa, aumentando o seu poder de destruição (GOMES et al., 2013).

Os movimentos gravitacionais de massa são responsáveis por danos à infraestrutura, perdas de vidas e sérios prejuízos socioeconômicos. A combinação de áreas de relevo montanhoso com chuvas intensas e/ou prolongadas são os principais condicionantes para o desencadeamento de movimentos gravitacionais de massa (KIRSCHBAUM et al., 2010, 2012a; HONG et al., 2006).

O aumento populacional e o crescimento desorganizado das cidades conduzem para uma ocupação indevida das áreas de riscos (BANKOFF et al., 2004). Quando ocupadas por populações de baixa renda com adensamento populacional são, normalmente, desprovidas de estrutura urbana adequada, aumentando sua vulnerabilidade aos desastres. Nesta conjuntura, os movimentos gravitacionais de massa em aglomerados urbanos consistem em um "desastre de vulnerabilidade social", atingindo principalmente a população com menor renda, que acaba vivendo em áreas precárias devido às limitações econômicas (DOWLING et al., 2014; SANTI et al., 2010). Apesar das incertezas, Petley (2012) estimou que de 2.620 eventos de movimentos gravitacionais de massa (sem relação com sismos)que tiveram ocorrência fatal,durante um período de seis anos (2004-2010), resultaram num total de 32.322 mortes registradas. Estes movimentos gravitacionais de massa fatais estão 
intimamente correlacionados com a densidade populacional, ocorrendo principalmente no arco entre o Himalaia e a China. Aproximadamente 2,2 milhões de pessoas estavam expostas a movimentos gravitacionais de massa em todo mundo em 2009 (PEDUZZI et al., 2009).

O Estado do Rio de Janeiro possui diversos atributos físicos (áreas montanhosas com períodos de chuvas intensas no período de dezembro a abril) e antrópicos (alta densidade populacional sobre encostas) que favorecem a possibilidade de recorrência periódica de eventos de desastres naturais do tipo de movimentos gravitacionais de massa, principalmente escorregamentos. Estudos desde a década de 1960 relatam diversos eventos que costumam ocorrer nas regiões serranas (JONES, 1973; MEIS e SILVA, 1968a, 1968b; OGURA e FILHO, 1991).

O evento de maior magnitude ocorrido no Estado do Rio de Janeiro foi em janeiro de 2011, quando ocorreram 7.268 escorregamentos e corridas de massa na região Serrana do Estado do Rio de Janeiro. Nesse evento, sete municípios ficaram em situação de calamidade pública: Nova Friburgo, Petrópolis, Sumidouro, Teresópolis, São José do Vale do Rio Preto, Bom Jardim e Areal, totalizando 887 vítimas, 13.741 desabrigados e 22.496 desalojados (MINISTÉRIO DA SAÚDE, 2011).

Deste modo, a identificação das áreas susceptíveis a escorregamentos é um fator primordial para a elaboração de estratégias para a mitigação dos desastres e, consequentemente, diminuição ou até mesmo anular as perdas humanas e prejuízos financeiros. Neste propósito, os fatores condicionantes da ocorrência dos escorregamentos devem ser entendidos e simulados com objetivo de prever os desastres e possibilitar um planejamento do uso e cobertura da terra mais eficaz e condizente com suas limitações (SLAYMAKER, 2000).Dentre os modelos de previsão de escorregamentos, destacam-se os baseados sobre conceitos físicos (MONTGOMERY et al., 1998; GUIMARÃES et al., 1999; GOMES et al., 2013). Beven e Kirby (1979) foram pioneiros na utilização da modelagem matemática em bases físicas. Diversos modelos têm sido desenvolvidos dentro desta linha de pesquisa, como: Shallow Slope Stability Model (SHALSTAB) (MONTGOMERY \& DIETRICH, 1994, 1998), Distributed Shallow Landslide Analysis Model (dSLAM) (WU \& SIDLE, 1995), Stability Index MAPPING (SINMAP) (PACK et al., 1998), SEEPM e SLOPE/W (GEOSTUDIO, 2005), Transient Rainfall Infiltration and Grid-Based Regional Slope-Stability Analysis (TRIGRS) (BAUM et al., 2008) e High Resolution Slope Stability Simulator (HIRESSS) (ROSSI et al., 2013).

A modelagem matemática constitui- se numa alternativa eficaz para o mapeamento de porções da paisagem que apresentam risco à ocupação humana, necessitando de 
menores investimentos quando comparada com outras metodologias (MONTGOMERY et al., 1994; GOMES et al., 2008; GOMES et al., 2013).

Os modelos em bases físicas necessitam como dados de entrada parâmetros morfométricos (declividade e área de contribuição) e reológicos (ângulo de atrito, densidade, coesão do solo e a espessura do solo). Os atributos morfométricos podem ser extraídos de Modelos Digitais de Terreno (MDT) e/ou de Superfície (MDS).

O MDS representa a elevação do terreno da região contendo os elementos contidos sobre ele tais como cobertura vegetal e edificações, enquanto que no MDT as elevações dos elementos que estão sobre o relevo são extraídas. Por exemplo, se a área a ser investigada possui vegetação no MDS terá a elevação a partir das copas das árvores, diferentemente do MDT que terá a elevação do terreno em que está a vegetação (Figura 1). Esta diferença nos valores de elevação poderá ocasionar distorções na modelagem de escorregamentos.

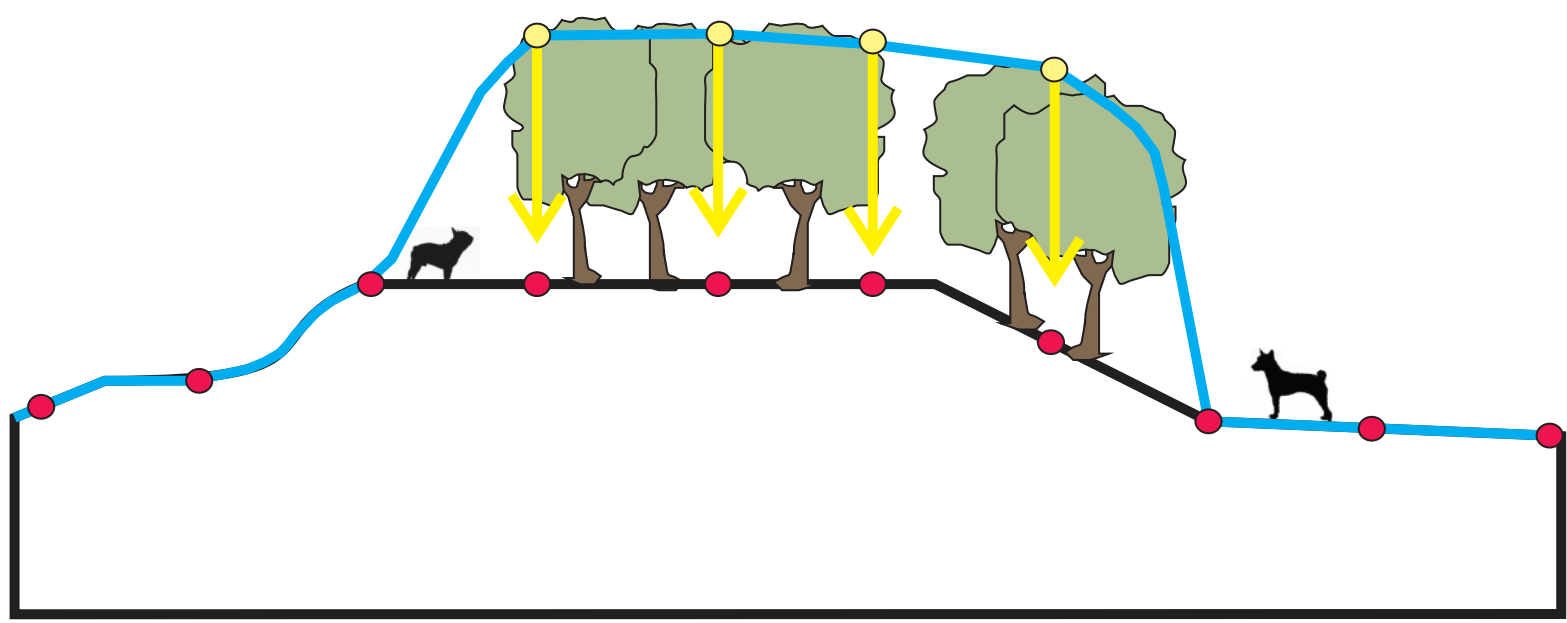

Figura 1- Figura esquemática da representação dos pontos de elevação extraídos do modelo digital de terreno (linha preta e pontos vermelhos) e do modelo digital de superfície (linha azul e pontos amarelos).

Os dados reológicos são obtidos a partir de teste em campo ou laboratório, o que dificulta a sua obtenção para extensas áreas. Outra forma de obter os parâmetros reológicos é a partir da técnica de retroanálise, que realiza a comparação de diversas simulações, adotando diferentes valores desses atributos, com as áreas de ocorrência dos movimentos gravitacionais de massa. Os parâmetros reológicos adequados serão os referentes à simulação que obtiver o melhor ajuste com a ocorrência dos movimentos gravitacionais de massa. Guimarães et al. (2003) adotou esta técnica para estimar os parâmetros reológicos nas áreas de escorregamentos na bacia hidrográfica do Quitite e Papagaio no Rio de Janeiro, considerando 125 simulações utilizando o modelo SHALSTAB. Gomes et al. (2013), 
utilizou a mesma abordagem só que para estimar os parâmetros reológicos das corridas de massa.

Neste intuito, o presente trabalho tem como objetivo aplicar a técnica de retroanálise a partir do modelo SHALSTAB na região da Serra das Araras, do Estado do Rio de Janeiro, e como objetivos específicos gerar os dados de elevação através de técnicas fotogramétricas, obtidos por meio da confecção de um modelo digital de terreno (MDT) e um modelo digital de superfície (MDS). A área escolhida possui um histórico de ocorrências de movimentos gravitacionais de massa. Em 1967, esta região teve um dos maiores eventos de movimentos gravitacionais de massa do país, deixando mais de mil pessoas soterradas (JONES, 1973). Além disso, a área é uma importante rota de infraestruturas, que interligam as cidades de São Paulo e o Rio de Janeiro, contendo rodovia (Dutra), estradas estaduais e vicinais, oleodutos e, possível implantação de trens de alta velocidade. 


\section{2 - ÁREA DE ESTUDO}

A área de estudo equivale a um recorte da Serra das Araras, nome local para a serra do Mar, localizada no município de Paracambi com área total de $19.176 .900 \mathrm{~m}^{2}$ na região sudoeste do Estado do Rio de Janeiro (Figura 2). A região possui um clima tropical e tropical de altitude (regiões com altitudes superiores a $1000 \mathrm{~m}$ ) com temperaturas médias anuais de $19^{\circ} \mathrm{C}$ e uma variação sazonal com um período chuvoso e outro seco (MORENO et al., 2003). Este ambiente com serras e planaltos do sudeste brasileiro age como uma barreira para a umidade que vem do oceano, o que aumenta consideravelmente o índice de chuvas, desencadeando diversos movimentos gravitacionais de massa ao longo das encostas de alta declividade (ROSS, 2008; TABARELLI e MANTOVANI, 1988).
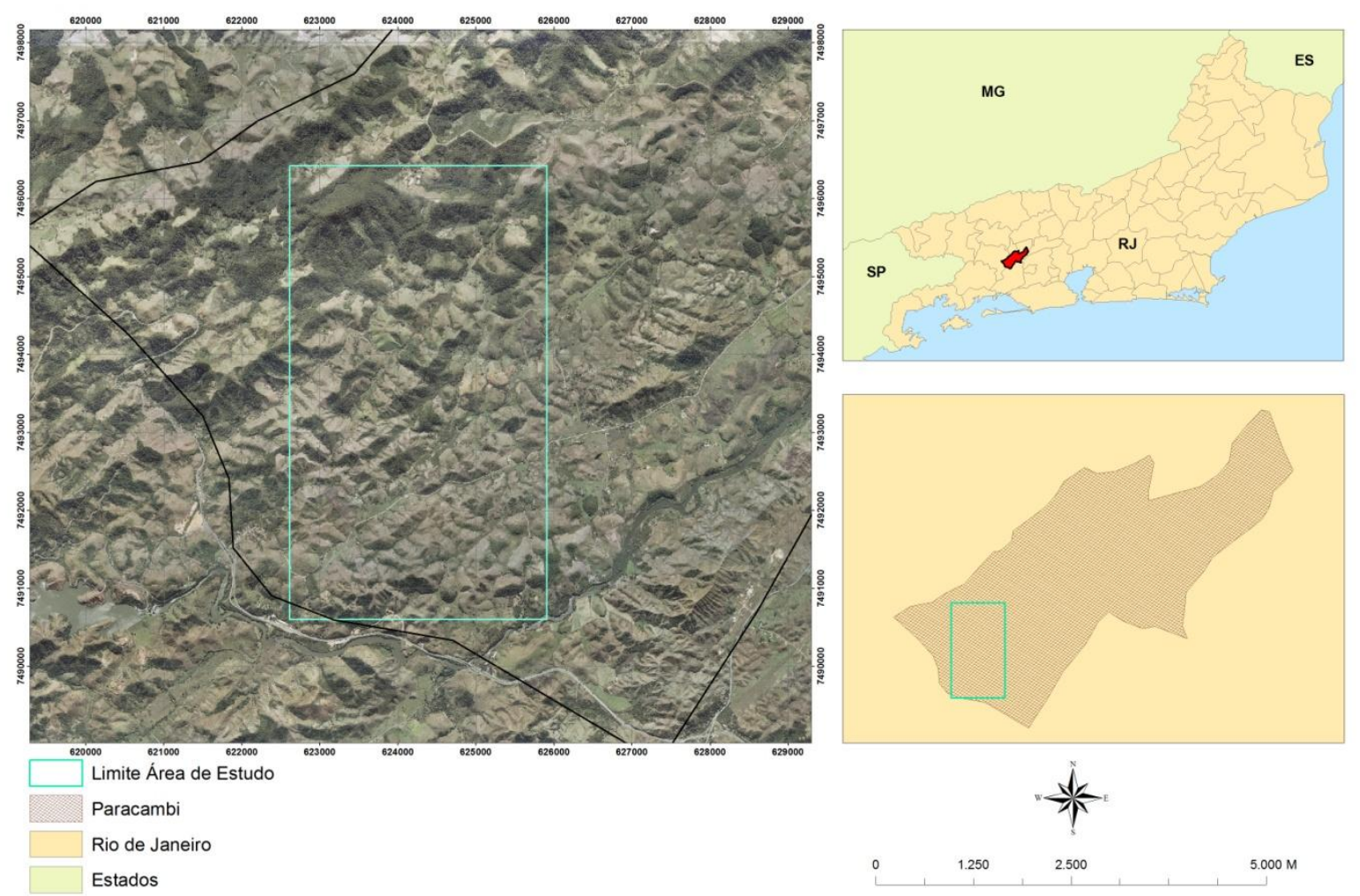

Figura 2 - Mapa de localização da área de estudo.

A Serra das Araras é composta basicamente por diferentes granitoides Neoproterozóicoscom composição granítica agranodioríticaricos em enclaves metassedimentares (calcissilicáticas, quartzitos, granada-biotita gnaisses) (MACHADO e DEMANGE, 1994). Estes leucogranitos aluminosos são granitos do tipo-S considerados como tardi-colisionais, provenientes de processos tardios ao espessamento tectônico da 
fase colisional, são oriundos da fusão parcial (anatexia) de rochas dominantemente metassedimentares e presentes nas zonas de cisalhamento dúcteis de baixo a alto ângulo (MACHADO e DEHLER, 2008). O planalto do médio vale do rio Paraíba do Sul é truncado pelas escarpas em recuo da Serra das Araras, correspondendo a subnivelamento local (ALMEIDA e CARNEIRO, 1998).

A Serra das Araras consiste em um ambiente transicional entre terrenos planos e colinas isoladas da Baixada da Septiba, com relevo colinoso da depressão Interplanáltica do médio Vale do rio Paraíba do Sul (SILVA, 2001). Desta forma, os altos índices pluviométricos aliados à inclinação dos taludes da Serra do Mar tornam essa área com alta incidência de movimentos gravitacionais de massa (GUIDICINI e NIEBLE,1983) (Figura 3). Os recorrentes movimentos gravitacionais de massa fizeram com que o Departamento de Recursos Minerais do Rio de Janeiro (DRM-RJ) elaborasse um mapa de risco iminente para o Estado do Rio de Janeiro baseado na ocorrência pretérita do fenômeno da região.
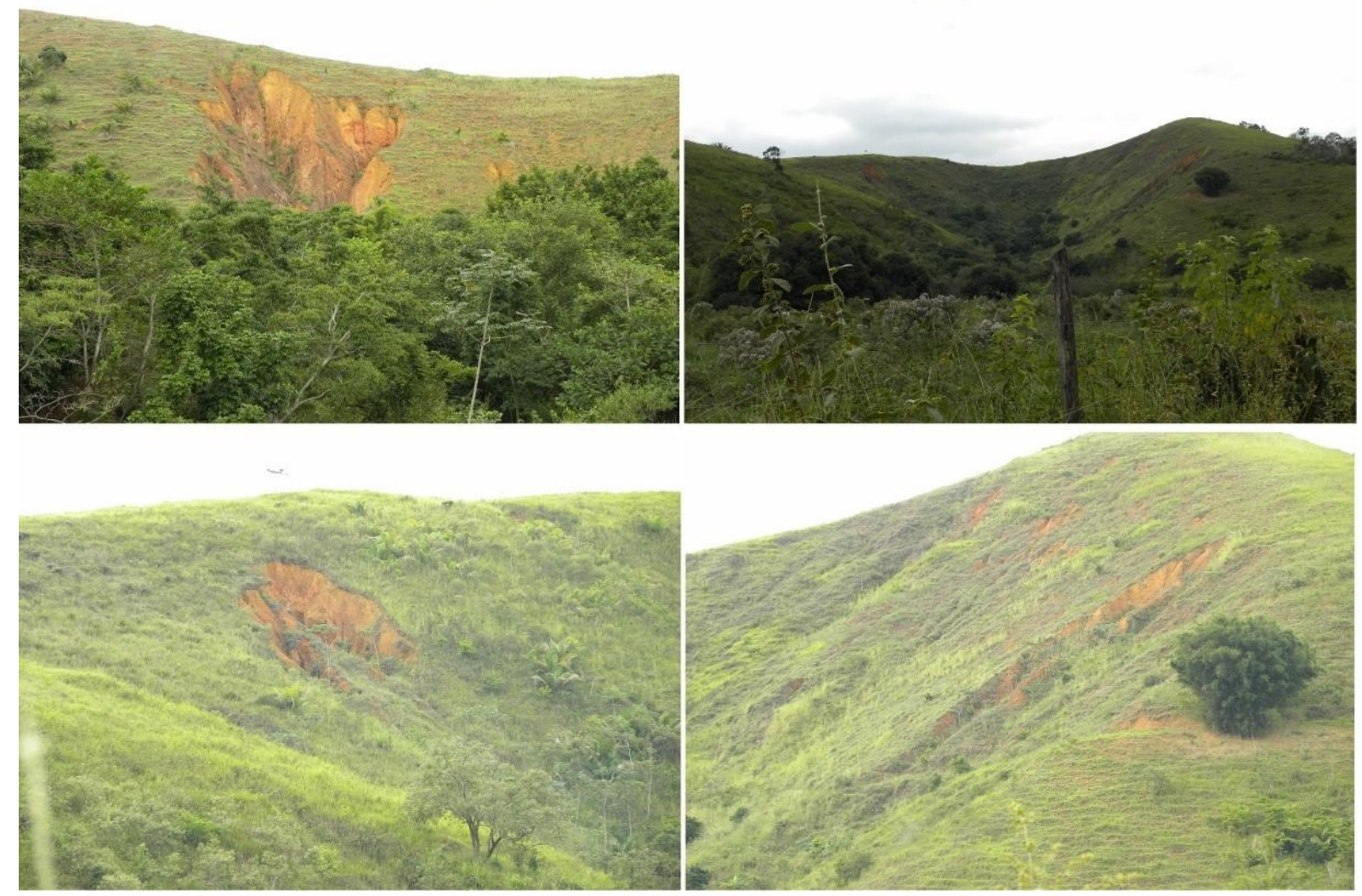

Figura 3 - Fotografias da área de estudo demonstrando cicatrizes de alguns movimentos gravitacionais de massa.

Na região que compreende a Serra do Mar, existem falhas geológicas que datam do período pré cambriano e se concentram a nordeste dessa região, essas falhas são recentes em relação ao contexto geológico e se desenvolveram a partir da reativação tectônica em 
zonas de fraqueza, e se apresentam no relevo por meio de cristas e escarpas truncadas ( HIRUMA et. al. 2001), áreas caracterizadas por falhas tendem a ser mais afetadas por escorregamentos devido aos ângulos das encostas e a elevada altitude (DOMINGUES).

A vegetação nativa da área é a Mata Atlântica, que devido à expansão agrícola e ao desmatamento apresenta uma significativa diminuição dos remanescentes florestais. A vegetação nativa encontra-se preservada em parques e unidades de conservação (PEIXOTO, 2004). A floresta apresenta árvores de médio e grande porte dentro de um ambiente fechado e denso, com alta biodiversidade vegetal e animal, desenvolvendo sobre solos pobres, porém recobertos por grande quantidade de matéria orgânica (MORENO et al., 2003). 


\section{3 - MATERIAIS E MÉTODOS}

A detecção das áreas susceptíveis a escorregamento foi realizada aplicando o modelo SHALSTAB, considerando um MDT e um MDS de resolução espacial de 5 metros extraídos das fotografias aéreas e parâmetros reológicos obtidos pela técnica de retroanálise. A metodologia adotada pode ser subdivida nas seguintes etapas: (a) confecção de MDS; (b) confecção do MDT; (c) geração dos parâmetros morfométricos (área de contribuição e declividade); (d) simulações com o modelo SHALSTAB, considerando diferentes valores dos parâmetros reológicos e os modelos digitais (MDT e MDS); e (e) validação e comparação por meio do mapeamento de cicatrizes. A Figura 4 apresenta um fluxograma das etapas realizadas no presente estudo.

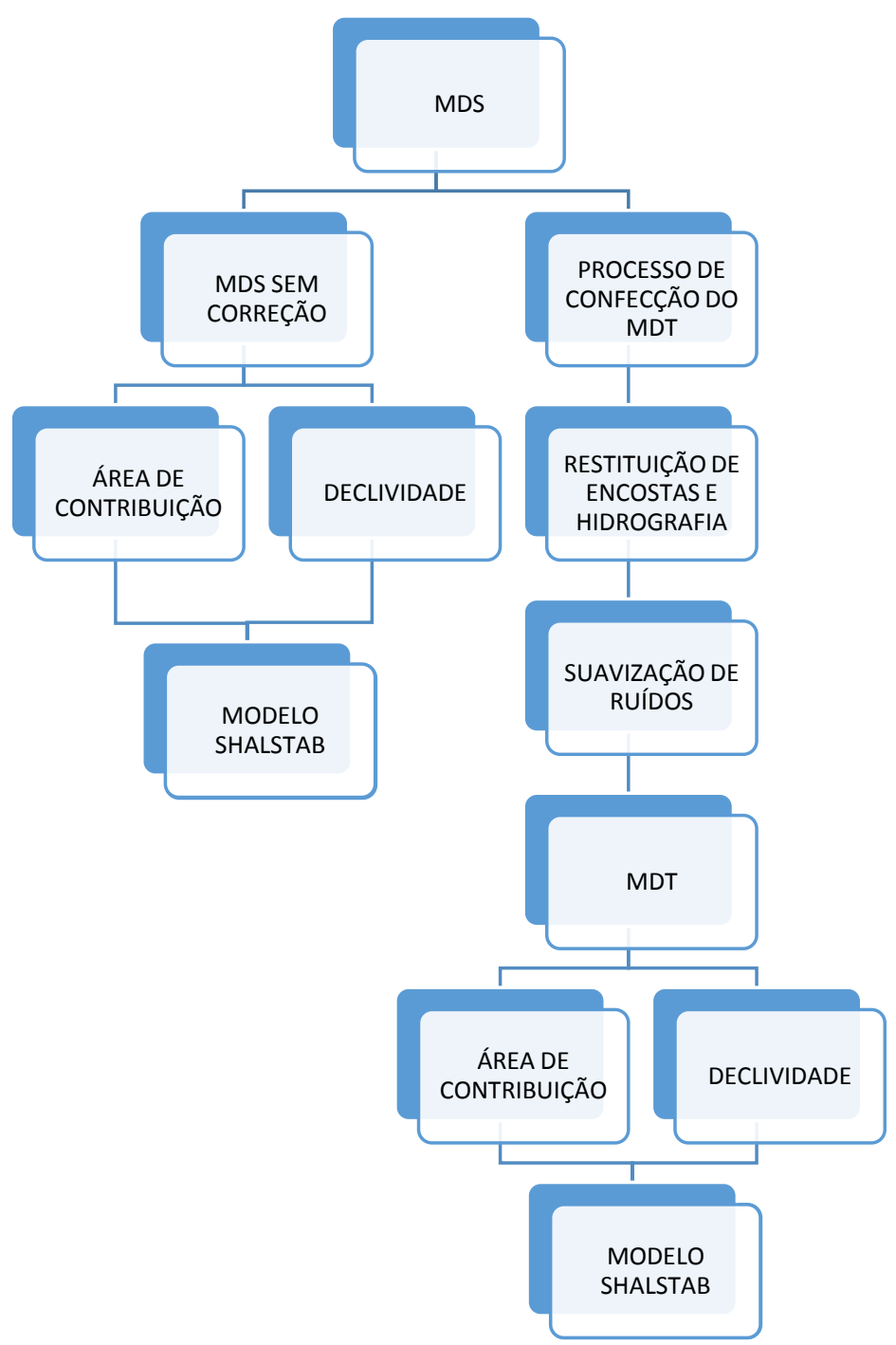

Figura 4 - Fluxograma da metodologia aplicada no trabalho. 


\section{1 - Elaboração do Modelo Digital de Superfície (MDS)}

Os modelos digitais podem ser obtidos por diversas formas: interpolação de cartas topográficas ou pela extração de imagens de sensores remotos. A interpolação dos dados das cartas topográficas é baseada em métodos geoestatísticos para obtenção dos valores referentes à elevação. A aquisição dos dados de elevação por sensores remotos é feita de forma contínua, pixel a pixel, considerando diferentes tipos de sensores: ótico, radar ou laser. Os sensores de radar utilizam uma frequência de onda emitida pelo sensor e a diferença do tempo do retorno desta onda indicará a elevação (HANSSEN, 2001; MADSEN et al., 1993). O laser emite diversos feixes de onda em alta frequência que ultrapassa a vegetação e atinge a superfície topográfica (WEHR, 1999), sendo amplamente utilizado para estudos de deslizamentos (JABOYEDOFF et al., 2012)

O Modelo Digital de Superfície (MDS) construído no presente trabalho foi obtido através da aplicação de técnicas fotogramétricas e uso de fotografias aéreas de alta resolução espacial. O levantamento aerofotogramétrico gera fotografias aéreas estereoscópicas que por diferença de paralaxe possibilita obter o MDS. Ele contém artefatos, tais como: vegetação (copas das árvores) e edificações. Os avanços das técnicas de fotogrametria têm possibilitado a extração dos dados de elevação de maneira mais rápida e fidedigna. No entanto, a construção dos modelos digitais necessita de algoritmos e programas específicos que considerem os dados referentes a cada foto na hora de sua aquisição. Dados como orientação, inclinação e altitude do avião, entre outros.

No presente trabalho foram utilizadas fotografias aéreas analógicas do projeto RJ-25 relativas no ano de 2006, cedidas pelo Instituto Brasileiro de Geografia e Estatística (IBGE). As fotografias possuem resolução espacial de 0,7 metros e a câmera utilizada foi a Zeiss RMK Top 15, com distância focal de $152.749 \mathrm{~mm}$. As fotografias têm recobrimento estereoscópico de $60 \%$ no sentido longitudinal e de 30\% na lateral. A geração do MDS foi realizada no módulo MATCH-T DSM, do sistema fotogramétrico INPHO, a partir dos pares estereoscópicos das fotografias (Figura 5). A plataforma INPHO 3D apresenta as seguintes vantagens: permite a remoção dos objetos como edificações e vegetação, alta capacidade de gerar nuvens de pontos de alta densidade com tempo de processamento curto, tratamento de dados provenientes de sensor laser, gera produtos de alta qualidade em três dimensões e automatiza processos onerosos na fotogrametria (TON e TRAN, 2015; ROTTENSTEINER et al., 2013; HÖHLE, 2012 e AHN e SCHU, 1997).

Na elaboração do MDS são necessários os arquivos de metadados referentes a cada fotografia (extensão *.sup), que são inseridos no núcleo de gerenciamento de projetos do INPHO (ApplicationMaster). O arquivo de metadados contém as informações sobre a 
câmera utilizada na captura, a altitude do vôo, os dados do sistema inercial e de rotação, dentre outros.

Para construção do modelo digital através de técnicas fotogramétricas são necessárias todas as informações sobre orientação interior, orientação exterior, dados da câmera utilizada. A orientação exterior e interior das fotografias foi utilizada com o objetivo de alcançar a posição e a altitude de cada foto em relação ao avião. A orientação exterior foi realizada de forma automática a partir das informações do arquivo de metadados e a orientação interior foi realizada de forma manual a partir dos pontos de aerotriangulação de cada fotografia. A orientação interior tem como objetivo a reconstrução do feixe de perspectiva, ou seja, a referência da imagem em relação à câmara no momento da tirada da foto.

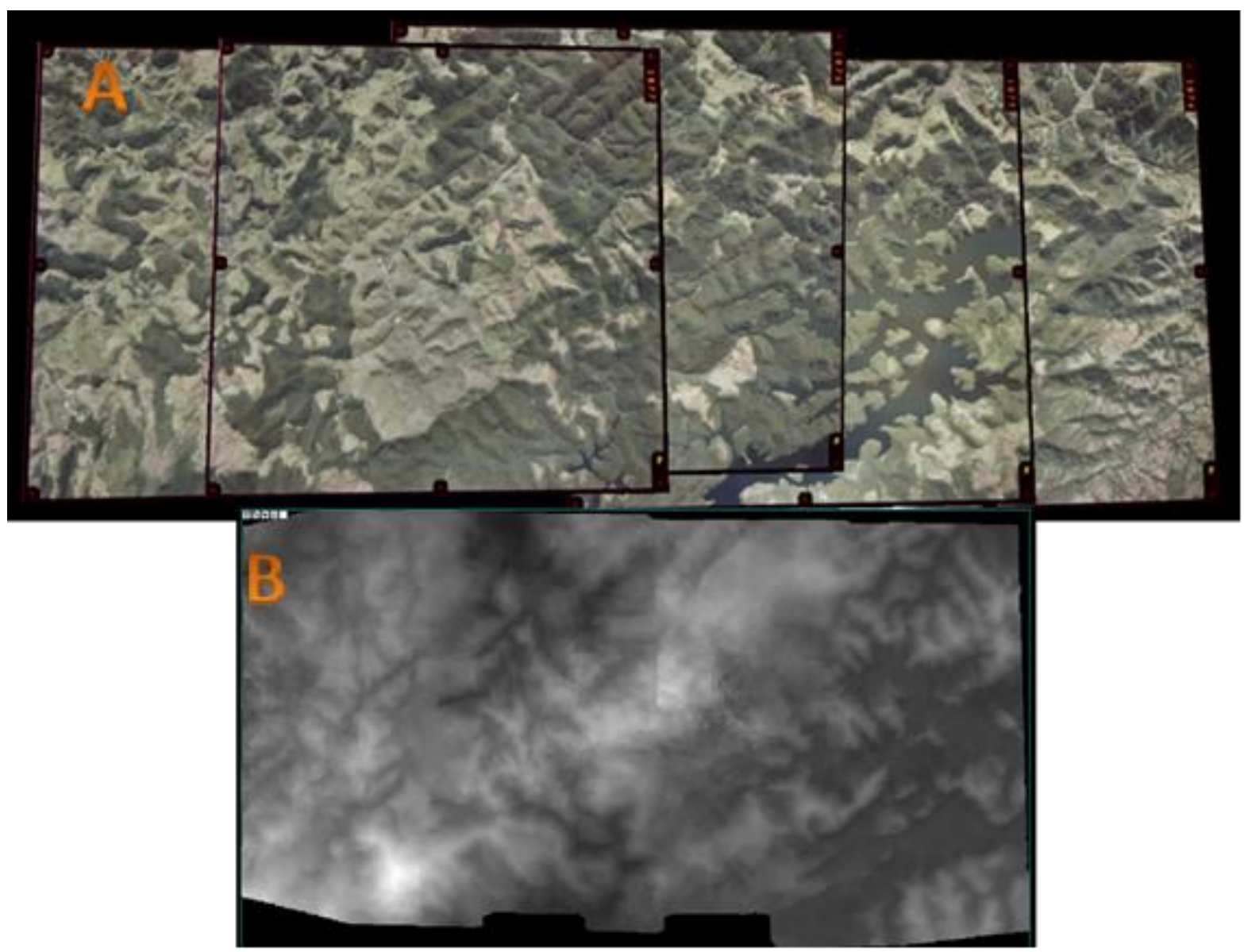

Figura 5 - Exemplo dos pares estereoscópicos utilizados para a geração do MDS no INPHO. 


\section{2 - Confecção do Modelo Digital de Terreno (MDT)}

O MDT utilizado no trabalho foi obtido a partir de edições e suavizações realizadas diretamente na nuvem de pontos do MDS. Essas modificações foram realizadas com o objetivo de manipular as cotas altimétricas relativas aos objetos que se encontravam acima do terreno, como vegetações e edificações, para que o MDT representasse apenas a topografia do relevo.

O processo foi realizado no módulo DTMaster, do INPHO, utilizando técnicas de estereoscopia digital e óculos 3D. Esse programa possui diversas ferramentas para a interpolação e correção e torna possível a manipulação das nuvens de pontos. As edições foram realizadas utilizando como referência os estereopares (Figura 6) e a análise da nuvem de pontos através da ferramenta de perfil topográfico, que exibe o recorte selecionado em um cubo 3D. As interpolações modificam diretamente o relevo representado pelo MDT.

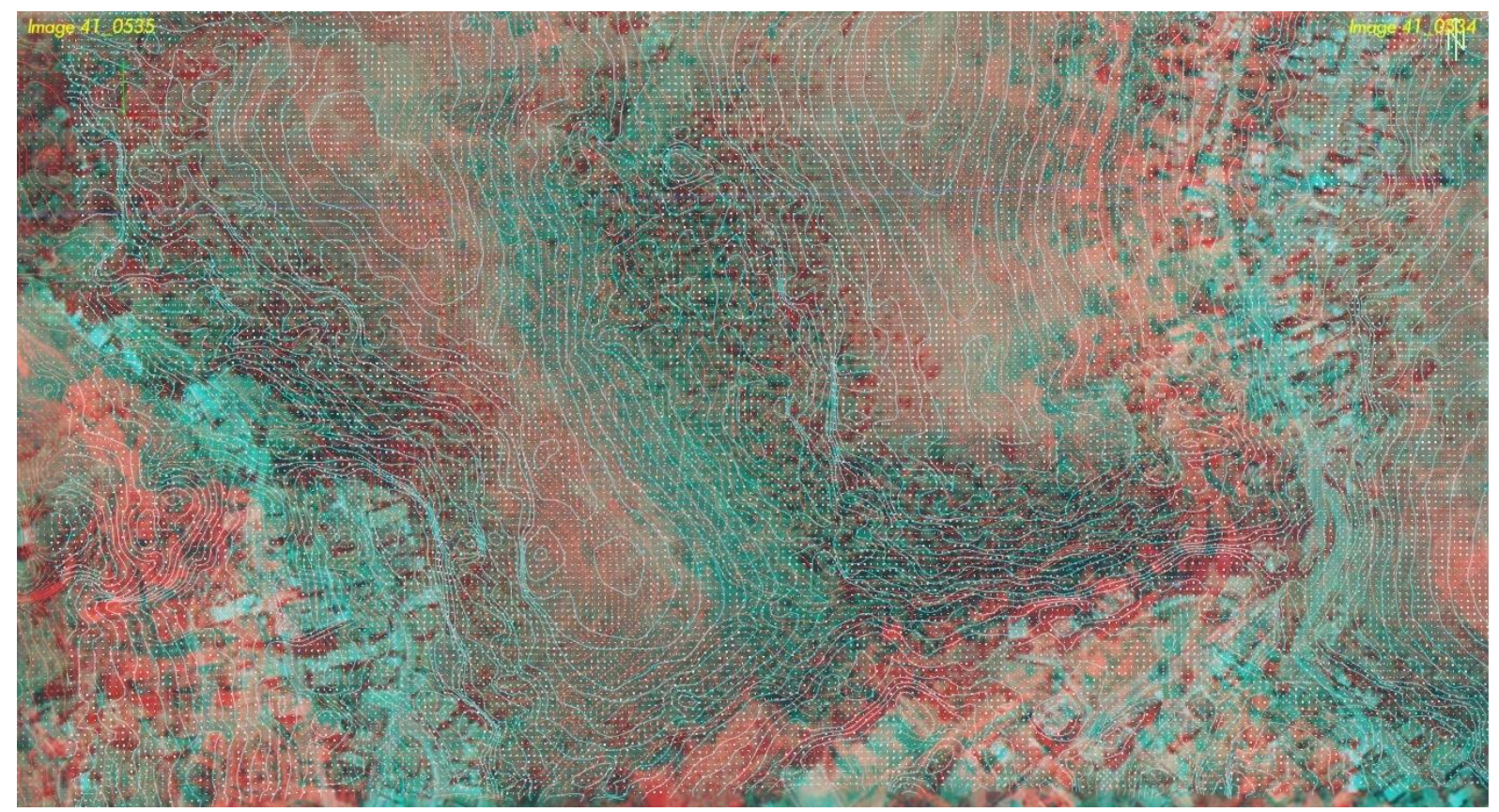

Figura 6- Modelo estereoscópico em que, as fotos e as curvas de nível estão sobrepostas ao MDS para seu tratamento e posterior geração do MDT.

As áreas cobertas por vegetação foram cuidadosamente corrigidas, devido à alta interferência na representação das encostas e linhas de drenagem. Para restituição da rede hidrográfica e melhoria das linhas de talvegue, linhas de apoio foram digitalizadas com base em visão estereoscópica por meio de óculos 3D (Figura 7). Essas linhas de drenagem foram utilizadas como base para suavização permitindo a interpolação dos pontos sem 
prejudicar a morfologia da encosta. Interpolações e filtragens para suavização foram realizadas nas áreas ruidosas com vegetação ou edificações que distorciam a real altimetria e forma da área.

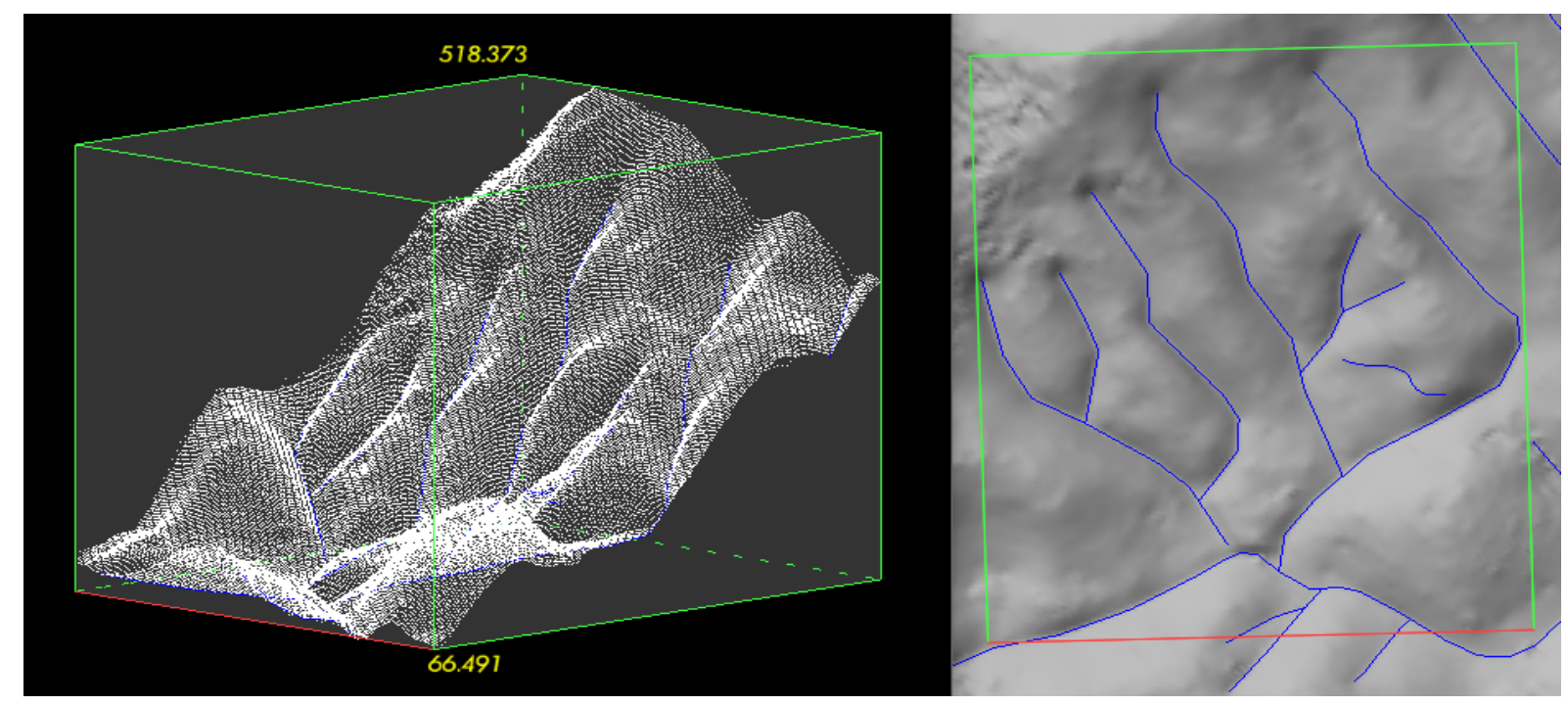

Figura 7-Superfície topográfica em 3D e as linhas de apoio utilizadas para suavização.

A Figura 8 apresentam os perfis topográficos, na forma de nuvem de pontos, das áreas contendo as linhas digitalizadas de apoio à interpolação. As linhas apresentam um afundamento em relação aos pontos do MDS, por causa das cotas altimétricas referentes às vegetações. Depois de interpolado, a nuvem de pontos é suavizada e a área editada acompanha as cotas altimétricas da linha digitalizada. Esse método de edição permite a manipulação da nuvem de pontos tendo como referência a visão estereoscópica dos estereopares, assim, outros pontos em que o MDS apresentava inconsistência puderam ser corrigidos.

As edições realizadas causaram grandes modificações no MDS, como pode ser observado na Figura 9. A área da esquerda, em que não foi realizado tratamento apresenta uma superfície mais "rugosa", devido à influência da vegetação, já a área editada (parte mais à direita) apresenta uma superfície suavizada e homogênea. Esta é uma importante etapa do trabalho, uma vez que a qualidade os mapas derivados dependem da consistência do MDT que será utilizado como base. 

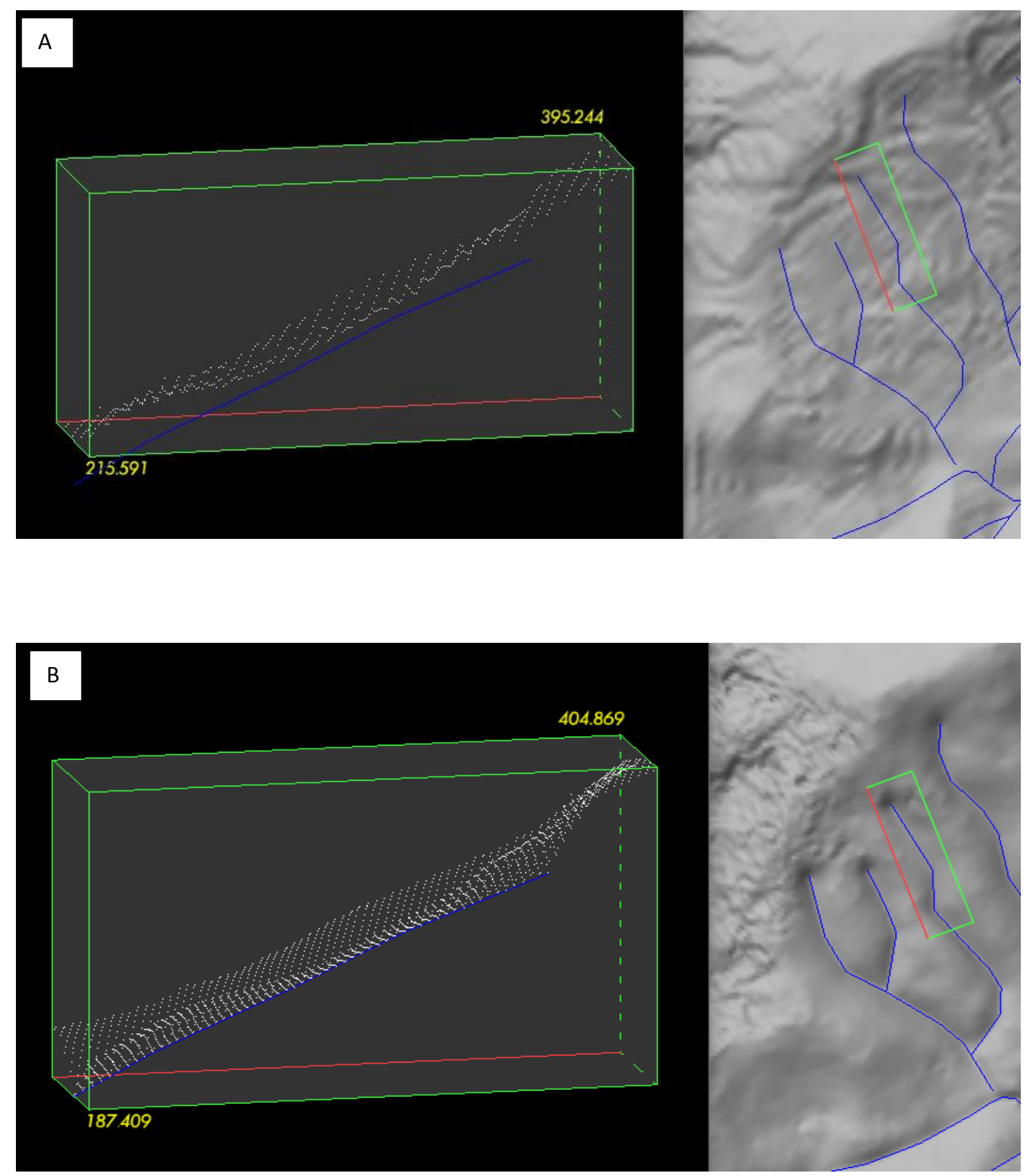

Figura 8 - (a) Perfil topográfico com nuvem de pontos antes da interpolação e (b) perfil topográfico com os pontos interpolados utilizando a linha de apoio. 

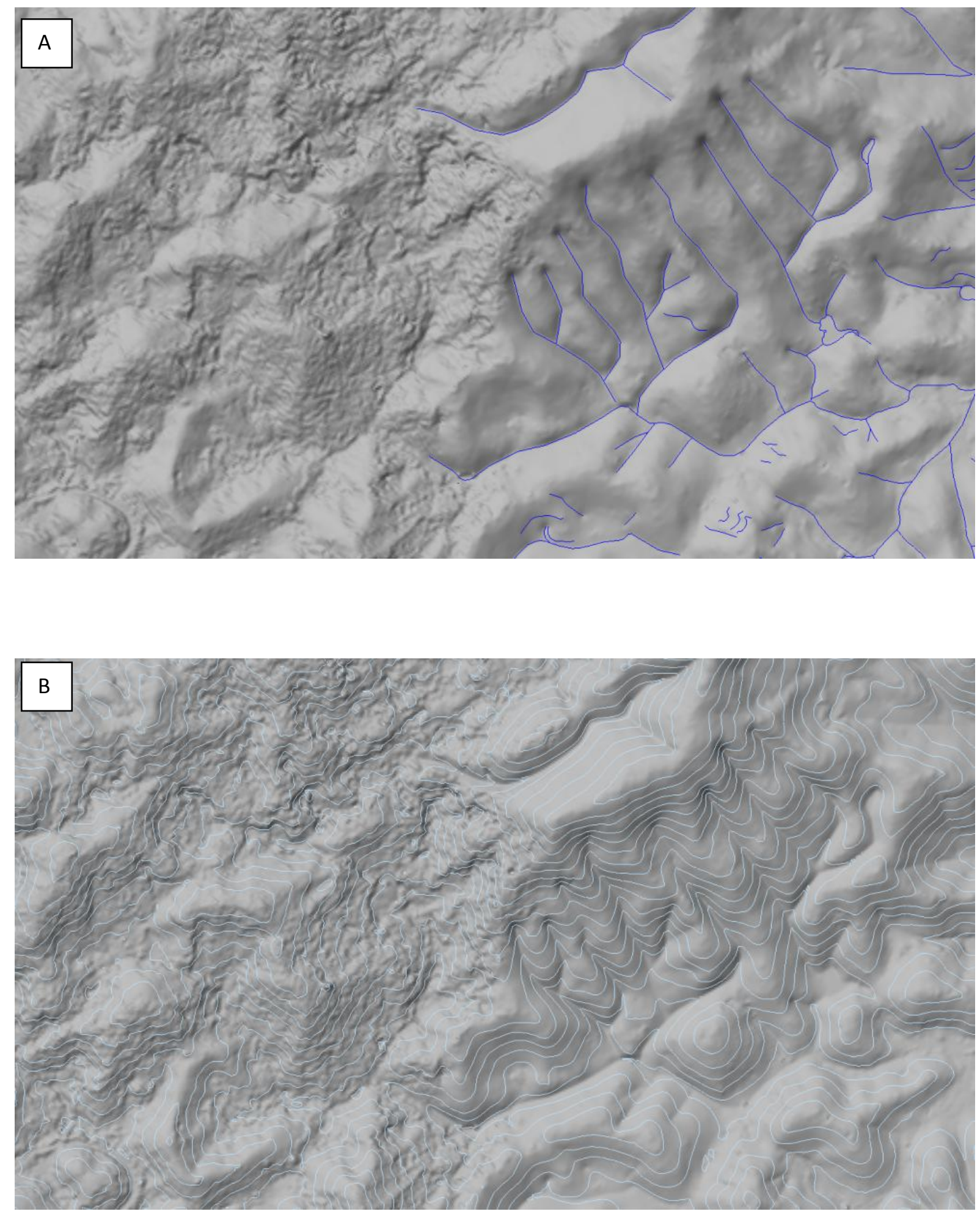

Figura 9 - Edições do MDS para obtenção do MDT (a) relevo sombreado e as linhas de drenagens e (b) relevo sombreado e as curvas de nível. 
A maioria dos lagos representados no MDS apresentou inconsistências na sua superfície, contento diversos valores de cotas altimétricas. A correção desses pontos foi realizada com a digitalização de um polígono em volta dele e com a definição da cota altimétrica única para todos os pontos que se encontravam no interior do polígono (Figura 10).

Dentro da área de estudo, as partes que demandaram maiores edições foram as encostas com vegetação, uma vez que a topografia e a rede de drenagem estavam sendo representadas de forma inconsistente. A Figura 11 demonstra o quanto as correções foram significativas nessas regiões. As nuvens de pontos do MDS e do MDT foram evidenciadas pela perspectiva tridimensional da ferramenta de perfil topográfico.
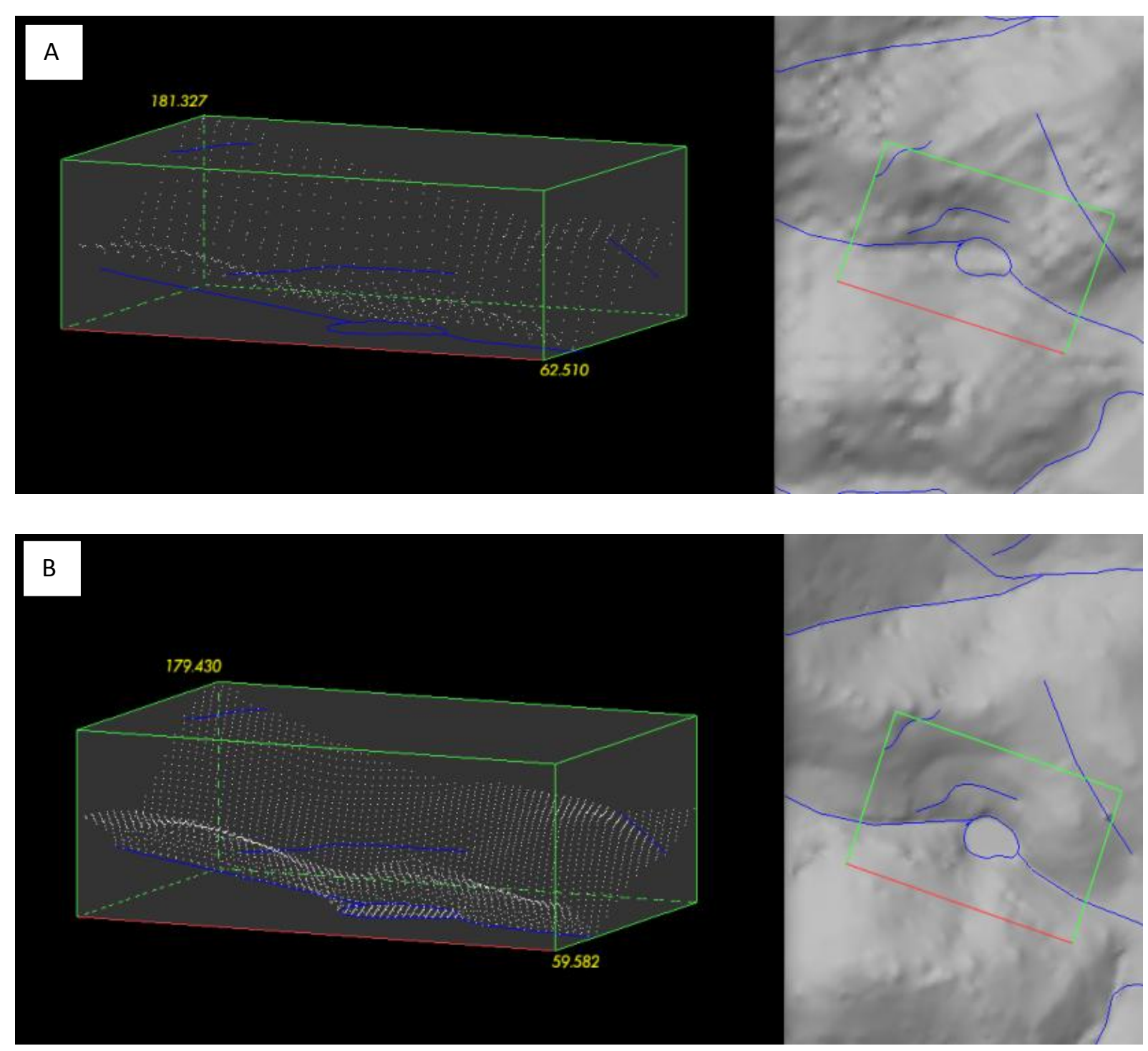

Figura 10 - Perfis topográficos de antes (a) e depois (b) da correção de lagos. 

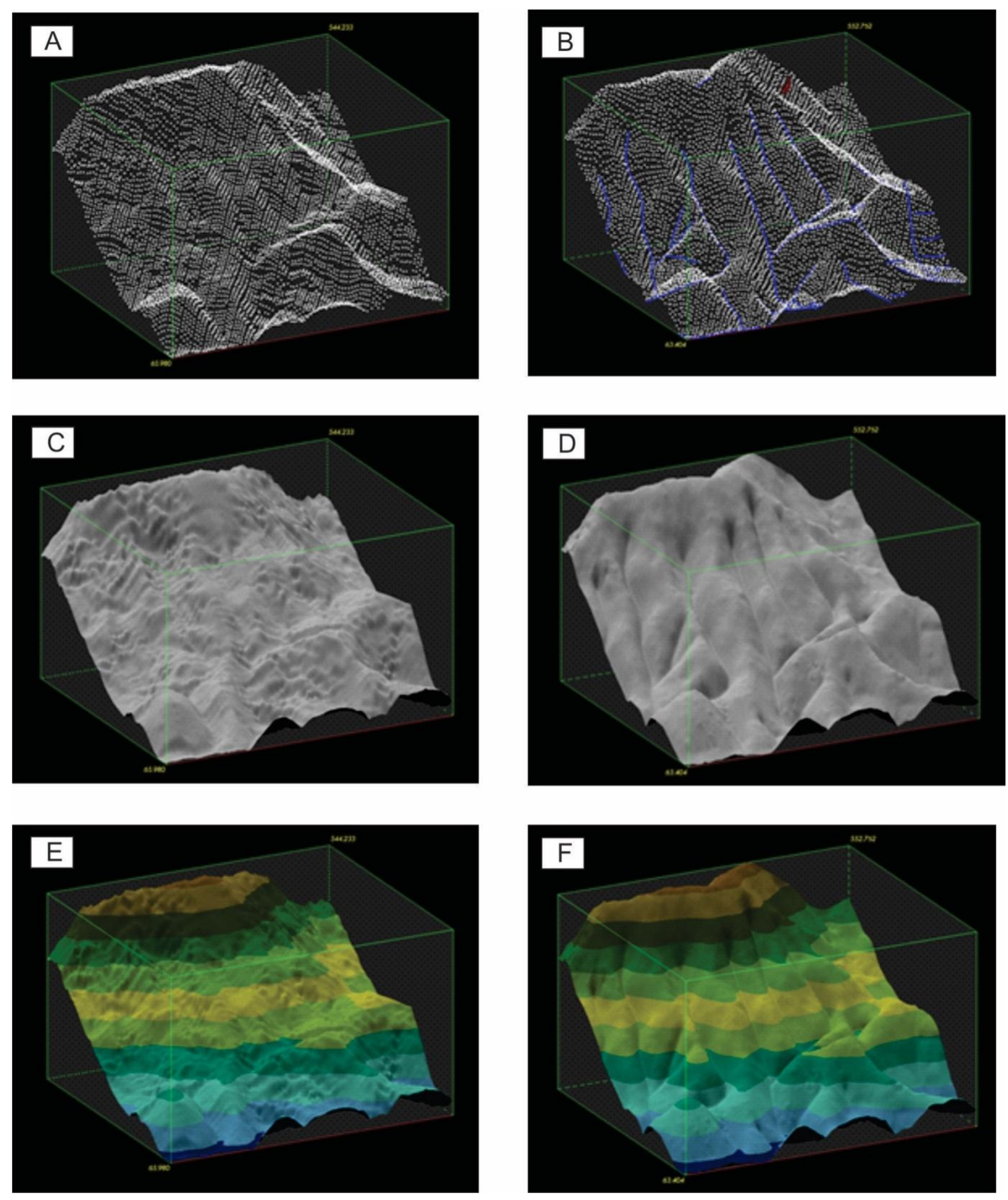

Figura 11 - Exibição da nuvem de pontos do MDS e MDT (A-B); exibição do relevo sombreado do MDS e MDT (C-D), exibição da superfície hipsométrica e relevo sombreado do MDS e MDT (E-F).

\section{3 - Obtenção dos parâmetros morfométricos}

Os atributos de terreno da área de estudo relativos à área de contribuição e declividade, essenciais para determinação das áreas de susceptibilidade a escorregamentos 
no modelo SHALSTAB, foram obtidos a partir do MDS e do MDT. É importante destacar que existem várias metodologias de cálculo da direção do fluxo de drenagem e das consequentes áreas de contribuição para cada célula do GRID. Neste trabalho foi utilizado o método de fluxo de direções múltiplas (Multi flow directions) (QUINN et al., 1991). Nesse método o fluxo é distribuído proporcionalmente em diversas direções à jusante, levando em consideração a declividade do local, e distribuindo o fluxo proporcionalmente.

A declividade, também foi estimada para cada célula do GRID. Para tanto, foi utilizada a rotina Slope implementada no software ArcGis 10. Esta rotina usa o modelo (no caso em questão o MDSe o MDT obtidos) para calcular o declive de cada célula do GRID,sendo esse estimado como uma média geométrica das direções que a declividade pode assumir a partir de uma determinada célula, utilizando as oito células adjacentes.

\section{4 - Simulações a partir do Modelo SHALSTAB}

O modelo SHALSTAB tem sido amplamente utilizado para a geração de mapas de susceptibilidade à ocorrência de escorregamentos em diversos locais do território brasileiro, tais como: Rio de Janeiro (GUIMARÃES et al., 2003; 2009;GOMES et al., 2005, 2013); Salvador (RAMOS et al., 2007); Caraguatatuba (VIEIRA\& RAMOS, 2015); Quadrilátero Ferrífero em Minas Gerais (RAMOS, 2002); Juiz de Fora (ZAIDAN \& FERNANDES, 2009), Vitória (SILVA et al. 2013) e no vale do rio Luis Alves em Santa Catarina (GERENTE et al., 2014).

O modelo SHALSTAB é um modelo para detectar áreas suscetíveis a escorregamentos, que combina um modelo hidrológico com um modelo de estabilidade de encostas (MONTGOMERY e DIETRICH, 1994a, b). O SHALSTAB é utilizado para prever a suscetibilidade de áreas a escorregamentos com transição do contato bem definida entre a porção mais permeável e impermeável (GUIMARÃES, 2000). O modelo de estabilidade de encosta adota a teoria do talude infinito que define a tensão tangencial de Mohr - Coulomb e é expresso pela seguinte equação:

$$
\mathrm{T}=\mathrm{C}^{\prime}+(\sigma-\mu) \tan \varnothing
$$

Onde $\mathbf{T}$ é a tensão tangencial, $\boldsymbol{\sigma}$ é a tensão normal, $\boldsymbol{\mu}$ é a poro pressão, C' é a coesão do solo e $\emptyset$ é o ângulo de atrito interno.

O modelo hidrológico é baseado no trabalho realizado por O'Loughlin (1986) que determina uma estimativa de umidade do solo levando em consideração o relevo, o ângulo da encosta e da transmissividade do solo. $O$ índice de saturação indicado por $\mathbf{W}$ é definido 
como a razão entre a quantidade de chuva $\mathbf{Q}$, que atinge determinada área e a capacidade de saturação do solo atingido.

$$
W=\left(\frac{Q \cdot a}{\text { t.b. } \operatorname{sen} \theta}\right)
$$

Onde "a" representa a área de contribuição, "b" o tamanho do lado da célula, " $\theta$ " a declividade e "t" a transmissividade do solo.

Conforme destacado por Montgomery e Dietrich (1994), estes dois modelos podem ser rearranjados para a razão de $\mathbf{h} / \mathbf{z}$ (que é a altura do nível de água sobre uma espessura de solo). Quando rearranjados para a razão de $\mathbf{h} / \mathbf{z}$ é possível sua combinação resultando num modelo em que, a quantidade de precipitação necessária pela transmissividade do solo num determinado ponto (num pixel), determina o nível de suscetibilidade para escorregamentos. Esse modelo pode ser expresso por duas equações, uma simples que não apresenta valores de coesão do solo, e outra composta, que apresenta valores de coesão, e são expressos respectivamente pelas seguintes equações:

$$
\begin{gathered}
\frac{Q}{T}=\frac{\operatorname{sen} \theta}{a / b}\left(\frac{P s}{P w}\right)\left(1-\frac{\tan \theta}{\tan \emptyset}\right) \\
\frac{Q}{T}=\frac{\operatorname{sen} \theta}{a / b}\left(\left(\frac{C^{\prime}}{P_{\cdot w} \cdot g \cdot z \cdot \cos ^{2} \theta \cdot \tan \emptyset}\right)+\left(\frac{P s}{P w}\right)\left(1-\frac{\tan \theta}{\tan \emptyset}\right)\right)
\end{gathered}
$$

As simulações referentes ao modelo SHALSTAB foram feitas com diferentes parâmetros. Tanto o MDS quanto o MDT, tiveram simulações realizadas com o ângulo de atrito 30 e 45, densidade aparente 1,5 e 2 e coesão de 0,2 e4. Foram utilizados estes valores de parâmetros do solo baseado no trabalho desenvolvido por Guimarães et al. (2003) que elenca os valores mais importantes para a coesão, densidade e ângulo de atrito, numa região com características fisiográficas similares às da Serra das Araras. Além disso, não havia dados coletados em campo da área. Ao todo foram realizadas vinte simulações com parâmetros reológicos diferentes e aplicados no MDS e no MDT. Os parâmetros utilizados estão descritos na Tabela 1.

Tabela 1 - Parâmetros utilizados na modelagem do SHALSTAB com base no MDS e MDT.

\section{MDS e MDT}

\begin{tabular}{c|c|c}
\hline \hline \multirow{2}{*}{ Ângulo de atrito 30 } & Densidade Aparente & Coesão do solo \\
\cline { 2 - 3 } & 1.5 & 2 e4 \\
\cline { 2 - 3 } & 2 & 2 e 4 \\
\hline \multirow{2}{*}{ Ângulo de atrito 45 } & Densidade Aparente & Coesão do solo \\
\cline { 2 - 3 } & 1.5 & 0,2 e4 \\
\cline { 2 - 3 } & 2 & 0,2 e4 \\
\hline
\end{tabular}




\section{5 - Mapeamento de Cicatrizes}

O mapeamento de cicatrizes foi feito no programa ArcGis 10 em um banco de dados do tipo geodatabase. A digitalização foi realizada tendo como base o mosaico confeccionado a partir das ortofotos fornecidas pelo IBGE. No mapeamento foram identificadas 39 cicatrizes de escorregamentos com uma área de $159.588 \mathrm{~m}^{2}$, correspondente a $0,83 \%$ da área total (Figura 12).

Os trabalhos realizados utilizando inventário de cicatrizes são importantes devido o registro de instabilidade que ocorrei em determinada região, o que torna possível analises e comparações temporais diferentes da mesma área ( LOPES, 2007). O mapeamento de cicatrizes por meio de ortofotos com alta resolução é um método eficaz, pois esse tipo de mapeamento permite a delimitação da cicatriz com alto grau de detalhamento (BITAR, 2014).

O Comitê Técnico Internacional para deslizamentos (JTC 1) incentiva a utilização do levantamento de cicatrizes, a fim de identificar e compreender de forma mais profunda as interações que condicionam os movimentos gravitacionais de massa. A criação de dados referentes a delimitação de cicatrizes também é muito importante para quantificar a existência de risco por meio de ferramentas SIG e também por meio de analise temporal é possível acompanhar a evolução da paisagem de áreas que sofrem com os movimentos gravitacionais de massa.(MENDONÇA et. al., 2013).

O registro dos movimentos gravitacionais de massa garante a análise do que ocorreu no passado e presente e permite a previsão de escorregamentos no futuro, e é subsidio para a modelagem de processos físicos (FERNANDES e AMARAL, 2003). O mapeamento de cicatrizes espacializa a distribuição dos escorregamentos, e por meio de SIG, é possível incorporar a esses dados como, tipo, tamanho e o estado da cicatriz (PARISE,2001).

Nesse contexto, a partir das cicatrizes mapeadas foram realizadas as análises de validação, com o objetivo de comparar o percentual de pixels de classes de susceptibilidade ao total de pixels contidos dentro das cicatrizes. Além disso, foram realizados, ainda, cálculos para definir os valores de mediana, máximo e mínimo e de percentil encontrados dentro de cada cicatriz. 


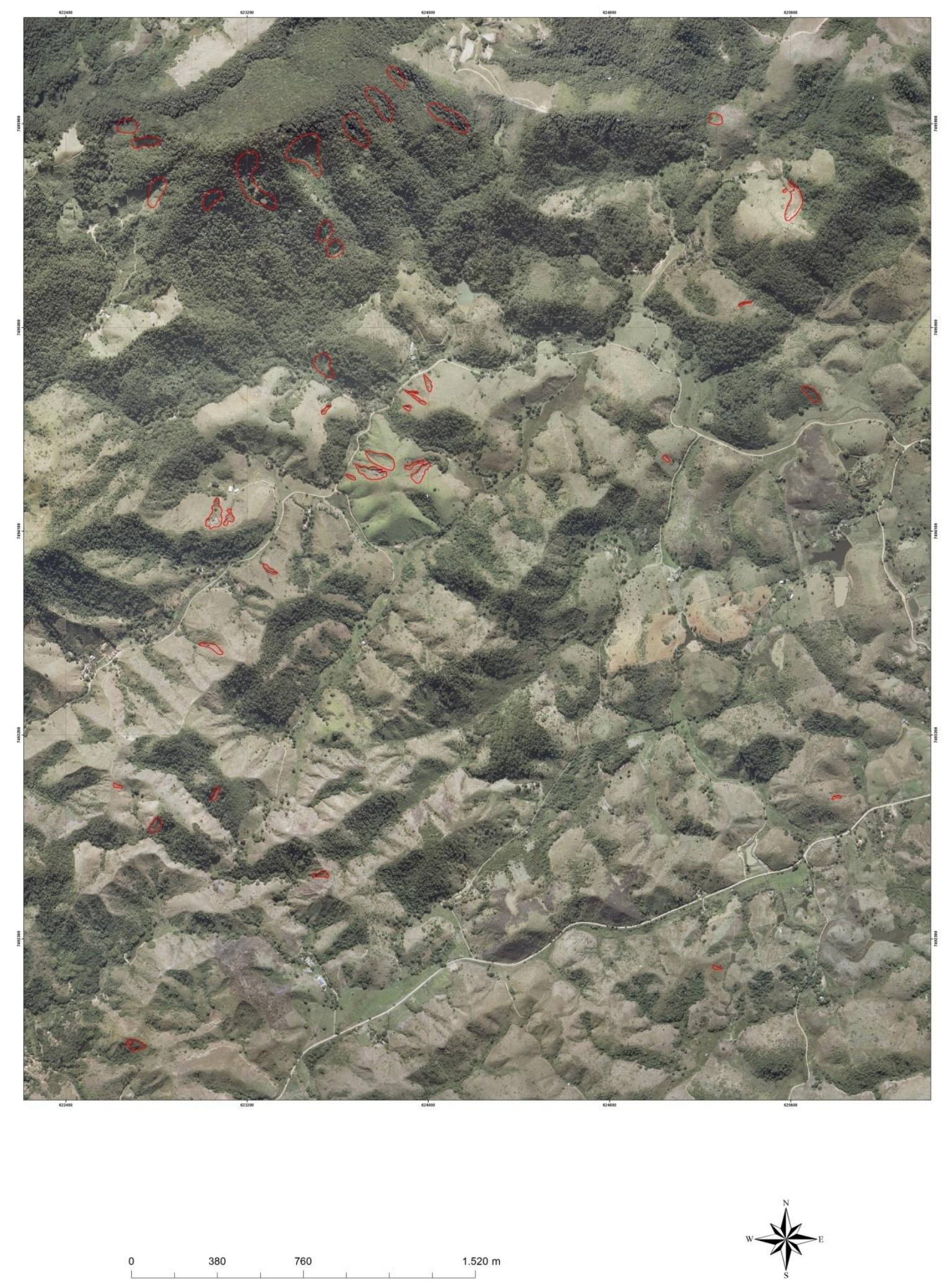

Figura 12 - Mapa das cicatrizes da área de estudos. 


\section{6 - Identificação do melhor modelo}

Na retroanálise, os parâmetros reológicos são estimados a partir de uma base de dados relativos aos eventos passados ou a partir de uma modelagem de auto ajuste com a realidade descrita. Assim, a retroanálise pode ser realizada de duas formas distintas, conforme a disponibilidade de dados: (a) quando o evento potencial ocorre em uma área com eventos anteriores bem documentados, os parâmetros reológicos calibrados de eventos pretéritos podem ser transferidos diretamente para a predição de eventos futuros (JORDAN, 1994); e (b) a dificuldade na obtenção de valores dos parâmetros reológicos, essa estimativa pode ser feita a partir de uma adequação de simulações com a realidade descrita em um procedimento de tentativa e erro (GUIMARÃES et al. 2003; MCDOUGALL e HUNGR 2004).

Em muitas regiões, as observações diretas em campo de movimento gravitacional de massa são extremamente difíceis de serem realizadas devido à dificuldade de acesso as áreas de ocorrência e a limitação de informações nos bancos de dados de casos reais. Portanto, as simulações numéricas providenciam mecanismos para a investigação dos parâmetros reológicos de avalanche de rochas (PIRULLI e MAGENEY, 2008, SOSIO et al. 2011), fluxo de detritos (BERTOLO e WIECZOREK 2005; GOMES et al. 2013; PIRULLI et al., 2011; PIRULLI e SORBINO, 2008) e escorregamentos (GUIMARÃES et al. 2003). Para realizar a retroanálise é necessário reconstruir as condições geotécnicas e geométricas da encosta no momento da ruptura (LOLLINO et al. 2014). A retroanálise determina o comportamento do escorregamento em função do material e suas propriedades intrínsecas e pode ser realizado através de análises controladas independentes antes de ser aplicada à análise de casos reais (SPREAFICO et al. 2014). A área de estudo carece de dados reológicos, sendo utilizado o procedimento de modelagem para a determinação de um modelo adequado de escorregamento.

Uma vez que os dados do MDT e seus atributos de terreno são definidos, os parâmetros reológicos são obtidos por meio de uma sequência de simulações, considerando variações dos parâmetros reológicos e a definição por tentativa e erro do modelo que se mais aproxima de uma configuração real. Portanto, a calibração dos resultados da retroanálise é sempre definida em relação aos dados de um protótipo real (MCDOUGALL e HUNGR, 2004), usando um índice específico para ranquear os melhores modelos em relação aos piores.

Guimarães et al. (2003) definiram um índice de ajuste do modelo (IAM) para a comparação das simulações dos escorregamentos modelados pelo SHALSTAB e as 
cicatrizes reais identificadas por fotointerpretação. O índice proposto consiste em uma porcentagem de pixels dentro da cicatriz em que o modelo predisse corretamente as zonas de instabilidade, sendo expresso como IAM=PMS/PS, onde PMS é o número de pixel predito corretamente dentro da cicatriz e OS é o número de pixel dentro da cicatriz. No entanto, esse índice considera apenas informações dentro das cicatrizes, privilegiando os modelos contendo valores de parâmetros reológicos com maior tendência a instabilidade. Para exemplificar, um mapa sendo completamente constituído por áreas instáveis acertaria todos os valores dentro das cicatrizes (obtendo um IAM de 100\%), mas erraria fora dela, o que não corresponderia a realidade. Guimarães et al. (2003) para contrabalancear esse comportamento do IAM realizou diferentes ranques adotando diversos percentis do número de áreas instáveis dentro das cicatrizes em relação ao número total de áreas instáveis mapeadas $(5,10,20$, e 30 percentis). Portanto, o modelo hipotético com apenas áreas instáveis dentro e fora das cicatrizes não estaria presente dentro dos percentis estabelecidos não sendo selecionado para a determinação dos melhores modelos. Desta forma, no trabalho de Guimarães et al. (2003)foram combinados dois índices: (a) IAM que condiz com a acurácia do produtor uma medida da probabilidade de acerto do modelo dentro da área verdadeira, e (b) a acurácia do usuário uma medida da probabilidade do acerto do modelo em relação a todos os pixels estimados. Story e Congalton (1986) descreveram as acurácias do usuário e do produtor.

Outra estratégia seria a utilização do índice de Exatidão Global (Overall Accuracy), que varia de acordo com o número de avaliadores, categorias e distribuição das amostras. O índice de exatidão global é uma métrica útil para avaliação de precisão de maneira geral, podendo ser utilizada para comparar quantitativamente e identificar o melhor modelo dentro de um processo de seleção (JENNES, 2005). O índice de exatidão global é obtido através da matriz de confusão, que compara a classe estimada em relação aos dados de referência, considerando apenas os elementos presentes na diagonal da matriz com o propósito de eliminar o elemento de casualidade, distribuição geral das amostras e produtos marginais (CAMPBELL 1987; LILLESAND et al., 2004). No presente caso, o índice de exatidão global estabeleceu uma proporção de acerto tanto nas áreas internas das cicatrizes, mas também em regiões externas das cicatrizes que não apresentavam escorregamentos. A delimitação da zona externa a cicatriz considerou um buffer ao redor das cicatrizes que proporcionasse ao mesmo tamanho da área interna da cicatriz. Desta forma, a área adotada na análise correspondeu aproximadamente ao dobro da área das cicatrizes, considerando uma proporcionalidade entre as classes da cicatriz e fora dela. Os diferentes modelos foram colocados em um ranque do maior para o menor índice de Exatidão Global. 


\section{4 - RESULTADOS E DISCUSSÕES}

\section{1 - Resultados dos MDT, MDS e de seus Atributos de Terreno}

A restituição fotogramétrica gerou um MDS com resolução espacial de 5 metros. $O$ tratamento do MDS para MDT permitiu um ganho de qualidade no modelo, que aumenta a confiabilidade do resultado na detecção das áreas susceptíveis a escorregamentos. A Figura 13 contrapõe o MDS e o MDT. O MDT apresentou um relevo mais suavizado com uma nítida melhora em relação às interferências dos artefatos do MDS. Os valores altimétricos variaram entre 40 a 600 metros (Figura 13a e13c). O MDT apresentou um histograma com uma distribuição mais homogênea e sem a presença de picos anômalos em comparação ao MDS(Figura 13d).

Os atributos de terreno utilizados no SHALSTAB a partir do MDS e MDT também evidenciam diferenças. A declividade do MDS salientou as feições sobre a superfície (vegetação) apresentando uma textura rugosa ao longo da encosta, principalmente, na porção noroeste (Figura 14a). Em contraposição, o mapa de declividade gerado a partir do MDT apresentou uma continuidade espacial, sem evidenciar uma fragmentação (Figura 14b). O histograma de frequência do mapa de declividade do MDS apresentou uma maior proporção de valores extremos do que o MDT, resultantes da presença dos artefatos sobre o relevo (Figuras 14c e 14d).

As áreas de contribuição do MDT e MDS apresentaram significativas mudanças com implicações na modelagem hidrológica (Figuras 15a e15b). Os artefatos no MDS alteraram significativamente a detecção correta das linhas de fluxo e dos divisores de drenagens (Figuras 15a e 15b). O MDT com a eliminação dos ruídos e artefatos sobre a superfície permitiu uma adequada representação das encostas e linhas de talvegue (Figuras 13a e 13b). O histograma de área de contribuição do MDT evidenciou uma concentração de valores intermediários, enquanto a área de contribuição gerada do MDS possui um maior espalhamento (Figuras 15c e 15d).

\section{2 - Resultados das Simulações com o SHALSTAB para o MDS}

As oito simulações foram realizadas proporcionando obter diferentes cenários de análise. As Tabelas 2 e $\mathbf{3}$ listam o número de pixels ou de porcentagem relativas às classes do modelo SHALSTAB a partir do MDS, considerando os diferentes valores dos atributos 
reológicos. As condições de instabilidades aumentam com a diminuição da coesão, densidade e ângulo de atrito.
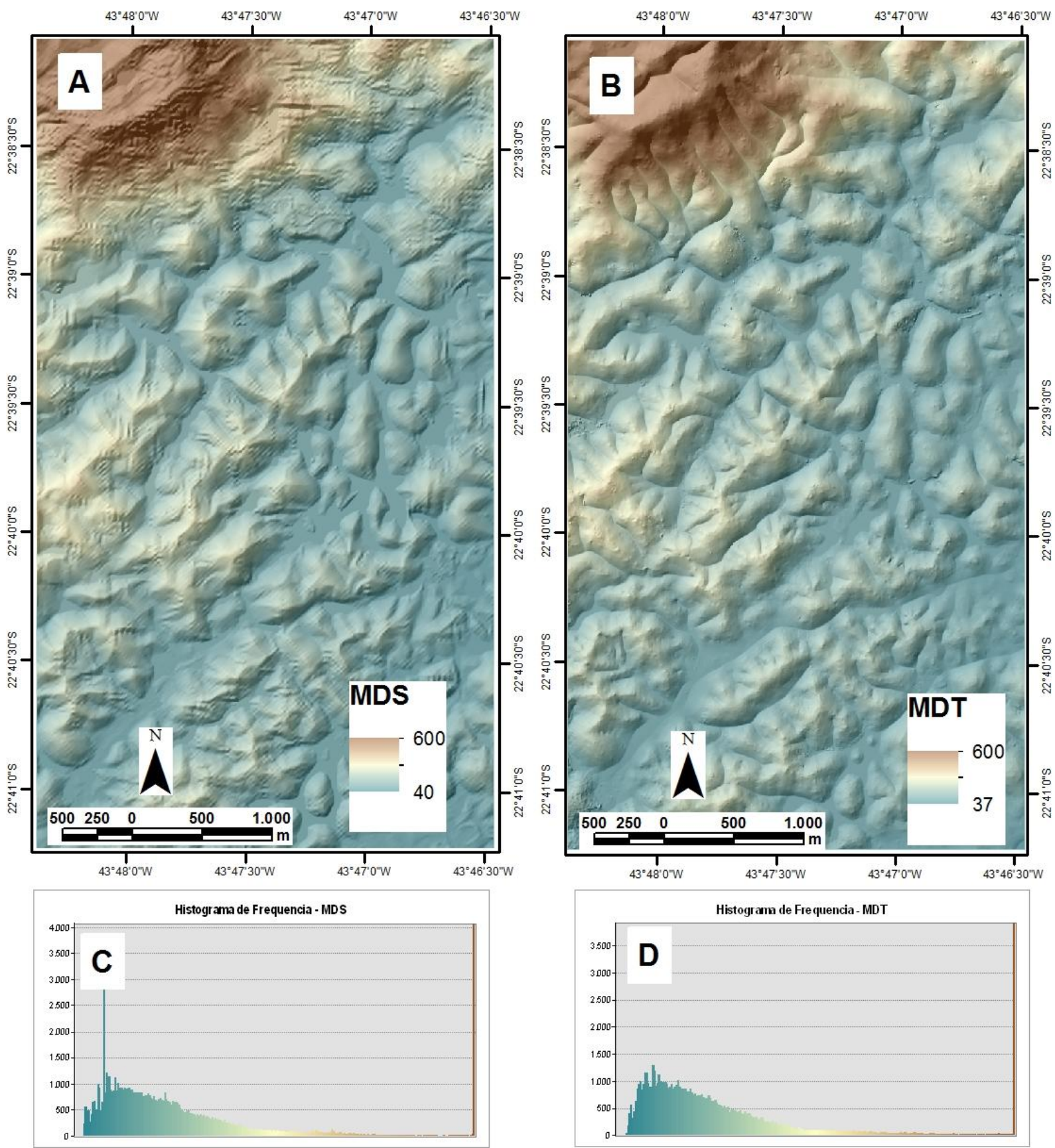

Figura 13 - (A) Mapa altimétrico a partir do MDS; (B) Mapa altimétrico a partir do MDT; (C) Histograma de frequência dos valores de altitude do MDS; (D) Histograma de frequência dos valores de altitude do MDT. 

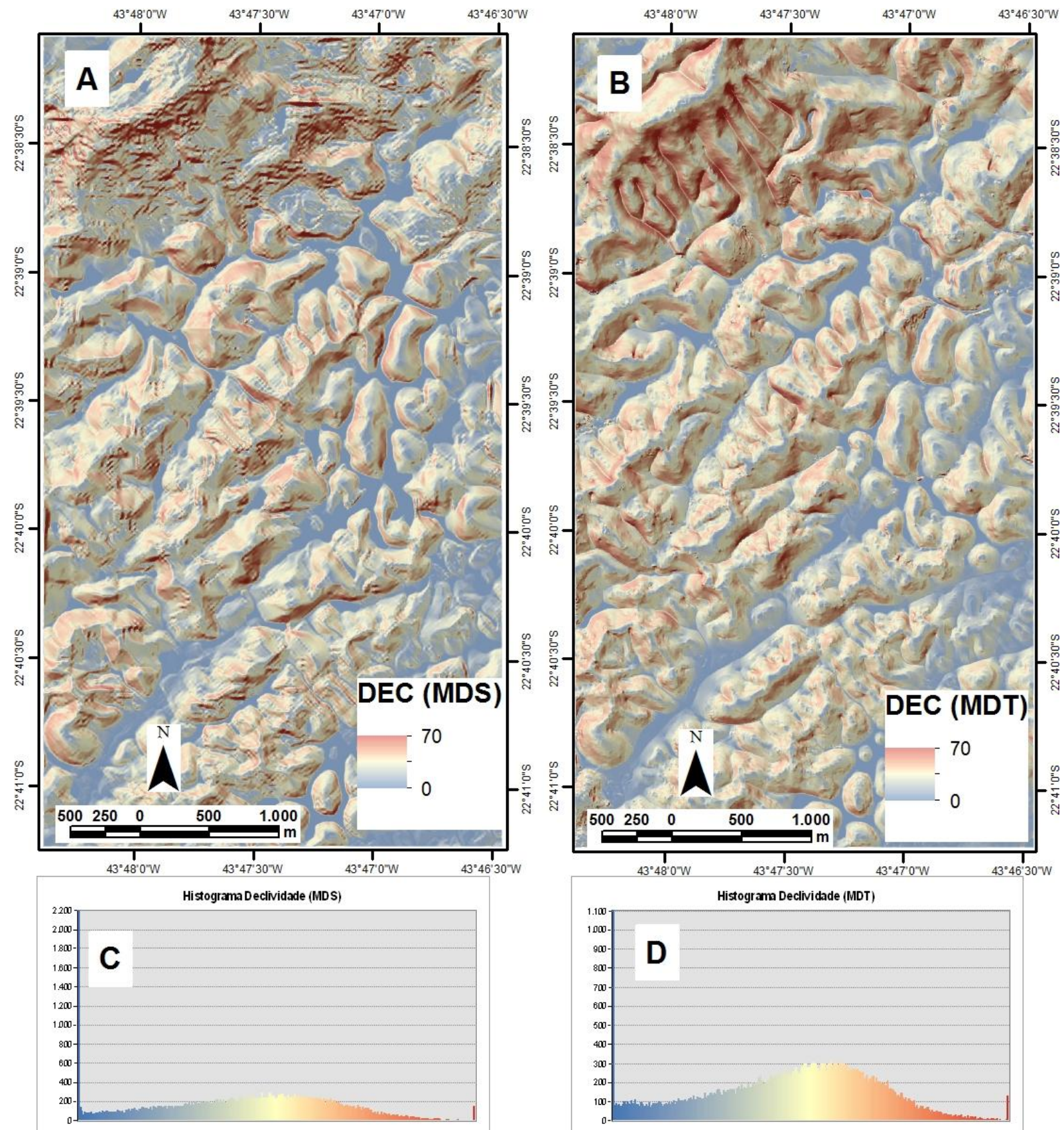

Figura 14 - (A) Mapa de declividade gerado do MDS; (B) Mapa de declividade gerado do MDT; (C) Histograma de frequência do mapa de declividade do MDS; (D) Histograma de frequência do mapa de declividade do MDT 

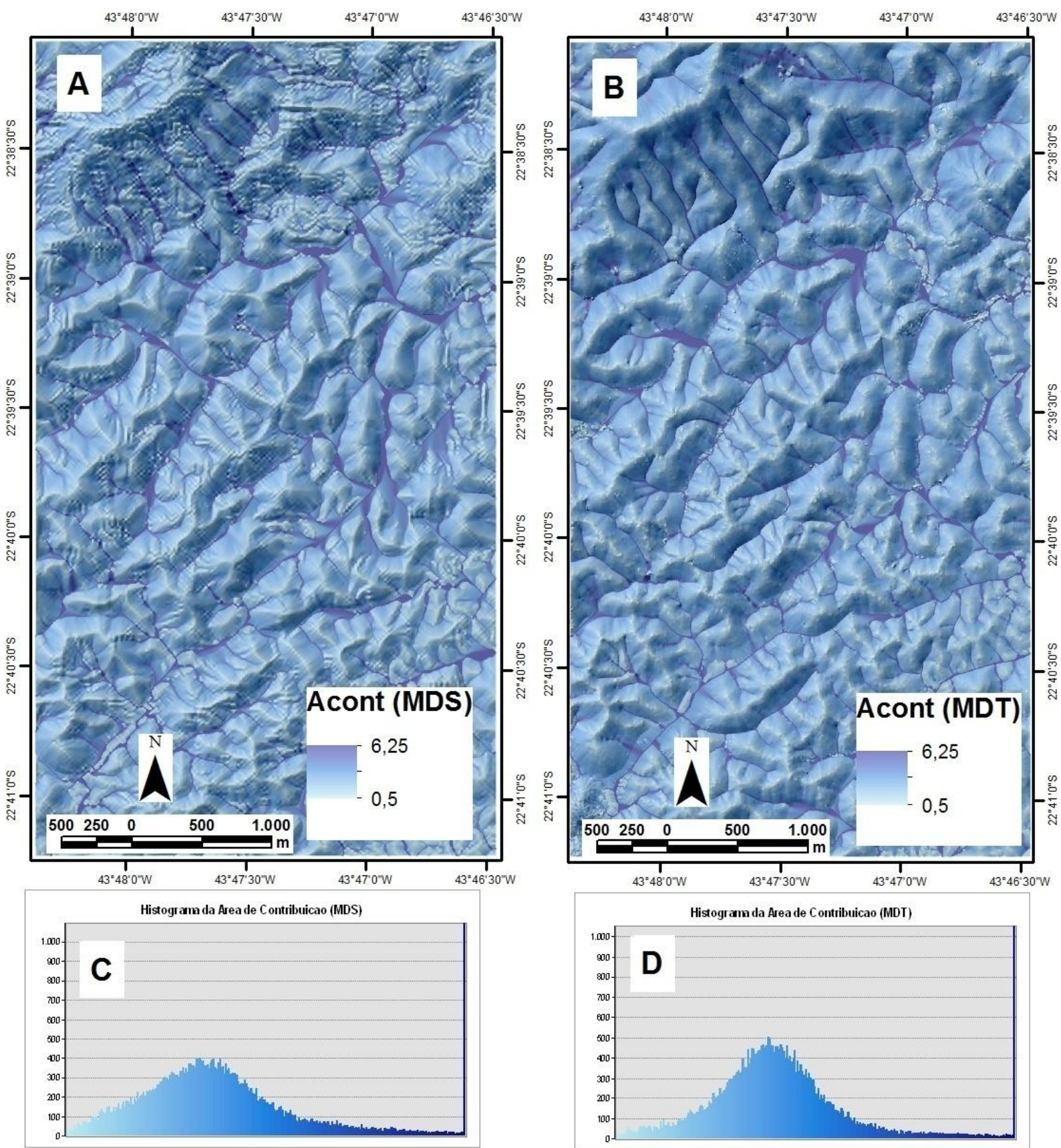

Figura 15 - (A) Mapa de área de contribuição gerado a partir do MDS; (B) Mapa de área de contribuição gerado a partir do MDT; (C) Histograma de frequência do mapa de área de contribuição do MDS; (D) Histograma de frequência do mapa de área de contribuição do MDT. 
Tabela 2 - O número de pixel dentro das cicatrizes relativas às classes do modelo SHALSTAB a partir dos dados MDS, considerando diferentes parâmetros reológicos.

\begin{tabular}{|c|c|c|c|c|c|c|c|c|c|c|c|c|}
\hline & \multicolumn{6}{|c|}{ ÂNGULO DE ATRITO - 45} & \multicolumn{6}{|c|}{ ÂNGULO DE ATRITO - 30} \\
\hline & \multicolumn{3}{|c|}{ DENSIDADE - 2} & \multicolumn{3}{|c|}{ DENSIDADE - 1,5 } & \multicolumn{3}{|c|}{ DENSIDADE - 2} & \multicolumn{3}{|c|}{ DENSIDADE - 1,5 } \\
\hline CLASSES & $\begin{array}{c}\text { COESÃo } \\
0\end{array}$ & $\begin{array}{l}\text { COESÃO } \\
2\end{array}$ & $\begin{array}{c}\text { COESÃO } \\
4\end{array}$ & $\begin{array}{c}\text { COESÃo } \\
0\end{array}$ & $\begin{array}{l}\text { COESÃO } \\
2\end{array}$ & $\begin{array}{c}\text { COESÃO } \\
4\end{array}$ & $\begin{array}{c}\text { COESÃO } \\
0\end{array}$ & $\begin{array}{l}\text { COESÃO } \\
2\end{array}$ & $\begin{array}{c}\text { COESÃO } \\
4\end{array}$ & $\begin{array}{c}\text { COESÃO } \\
0\end{array}$ & $\begin{array}{l}\text { COESÃO } \\
2\end{array}$ & $\begin{array}{c}\text { COESÃO } \\
4\end{array}$ \\
\hline $\begin{array}{l}\text { Incondicionalmente } \\
\text { Instável }\end{array}$ & 31 & 7 & & 31 & 3 & & 31 & 520 & 41 & 31 & 256 & 6 \\
\hline $0-50 \mathrm{~mm} / \mathrm{dia}$ & 57 & 14 & 1 & 168 & 46 & 3 & 57 & 354 & 48 & 168 & 333 & 37 \\
\hline $50-100 \mathrm{~mm} / \mathrm{dia}$ & 76 & 19 & 1 & 242 & 49 & 3 & 76 & 287 & 72 & 242 & 411 & 42 \\
\hline $100-200 \mathrm{~mm} / \mathrm{dia}$ & 328 & 66 & 2 & 664 & 184 & 6 & 328 & 548 & 270 & 664 & 765 & 185 \\
\hline $200-400$ mm/dia & 693 & 317 & 9 & 1149 & 639 & 83 & 693 & 648 & 581 & 1149 & 904 & 577 \\
\hline$>400 \mathrm{~mm} / \mathrm{dia}$ & 1312 & 786 & 130 & 1730 & 1544 & 285 & 1312 & 961 & 1045 & 1730 & 1239 & 1303 \\
\hline $\begin{array}{c}\text { Incondicionalmente } \\
\text { Estável }\end{array}$ & 3863 & 3863 & 3863 & 2376 & 2376 & 2376 & 3863 & 2007 & 2007 & 2376 & 1281 & 1281 \\
\hline $\begin{array}{c}\text { Incondicionalmente } \\
\text { Estável (para esta } \\
\text { coesão) }\end{array}$ & 0 & 1288 & 2354 & & 1519 & 3604 & & 1035 & 2296 & & 1171 & 2929 \\
\hline TOTAL & 6360 & 6360 & 6360 & 6360 & 6360 & 6360 & 6360 & 6360 & 6360 & 6360 & 6360 & 6360 \\
\hline
\end{tabular}

Tabela 3 - A porcentagem de área dentro das cicatrizes relativas às classes do modelo SHALSTAB a partir dos dados MDS, considerando diferentes parâmetros reológicos.

\begin{tabular}{|c|c|c|c|c|c|c|c|c|c|c|c|c|}
\hline \multirow[b]{3}{*}{ CLASSES } & \multicolumn{6}{|c|}{ ÂNGULO DE ATRITO - 45} & \multicolumn{6}{|c|}{ ÂNGULO DE ATRITO - 30} \\
\hline & \multicolumn{3}{|c|}{ DENSIDADE - 2} & \multicolumn{3}{|c|}{ DENSIDADE - 1,5 } & \multicolumn{3}{|c|}{ DENSIDADE - 2} & \multicolumn{3}{|c|}{ DENSIDADE - 1,5 } \\
\hline & MDS & MDS & MDS & MDS & MDS & MDS & MDS & MDS & MDS & MDS & MDS & MDS \\
\hline Instável & 0,49 & 0,11 & 0,00 & 0,49 & 0,05 & 0,00 & 0,49 & 8,18 & 0,64 & 0,49 & 4,03 & 0,09 \\
\hline $0-50 \mathrm{~mm} / \mathrm{dia}$ & 0,90 & 0,22 & 0,02 & 2,64 & 0,72 & 0,05 & 0,90 & 5,57 & 0,75 & 2,64 & 5,24 & 0,58 \\
\hline $50-100 \mathrm{~mm} / \mathrm{dia}$ & 1,19 & 0,30 & 0,02 & 3,81 & 0,77 & 0,05 & 1,19 & 4,51 & 1,13 & 3,81 & 6,46 & 0,66 \\
\hline $100-200 \mathrm{~mm} / \mathrm{dia}$ & 5,16 & 1,04 & 0,03 & 10,44 & 2,89 & 0,09 & 5,16 & 8,62 & 4,25 & 10,44 & 12,03 & 2,91 \\
\hline $200-400 \mathrm{~mm} / \mathrm{dia}$ & 10,90 & 4,98 & 0,14 & 18,07 & 10,05 & 1,31 & 10,90 & 10,19 & 9,14 & 18,07 & 14,21 & 9,07 \\
\hline$>400 \mathrm{~mm} / \mathrm{dia}$ & 20,63 & 12,36 & 2,04 & 27,20 & 24,28 & 4,48 & 20,63 & 15,11 & 16,43 & 27,20 & 19,48 & 20,49 \\
\hline Estável & 60,74 & 60,74 & 60,74 & 37,36 & 37,36 & 37,36 & 60,74 & 31,56 & 31,56 & 37,36 & 20,14 & 20,14 \\
\hline $\begin{array}{c}\text { Estável para esta } \\
\text { coesão }\end{array}$ & 0,00 & 20,25 & 37,01 & 0,00 & 23,88 & 56,67 & 0,00 & 16,27 & 36,10 & 0,00 & 18,41 & 46,05 \\
\hline TOTAL & 100 & 100 & 100 & 100 & 100 & 100 & 100 & 100 & 100 & 100 & 100 & 100 \\
\hline
\end{tabular}

As Figuras 16e 17 demonstram os mapas resultantes para os modelos SHALSTAB para as diferentes classes de instabilidade. Esses mapas repetem os erros provenientes do MDS apresentando um comportamento fragmentado nas áreas mais vegetadas, evidenciando a fragilidade do emprego desse tipo de dado para o mapeamento de áreas susceptíveis a escorregamento raso. As áreas com maior porcentagem de instabilidade ocorrem predominantemente na região noroeste da área onde ocorrem áreas com maior declividade. 


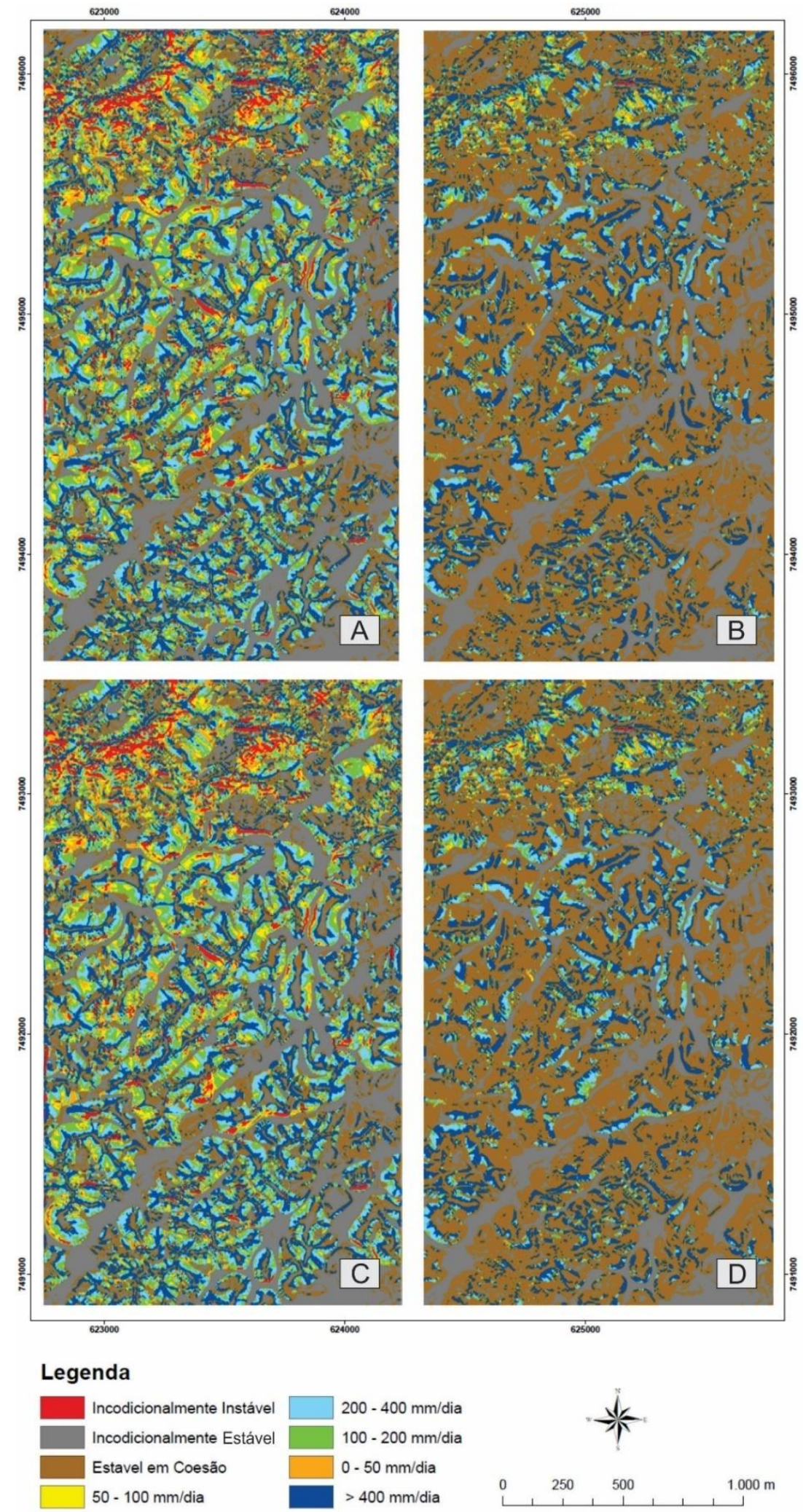

Figura 16 - Simulações do SHALSTAB utilizando os dados do MDS: (a) simulação 1 (C/z = 2, $\rho_{s} / \rho_{w}=1,5$ e $\left.\varphi=30\right)$, (b)simulação $2\left(\mathrm{C} / \mathrm{z}=4, \rho_{s} / \rho_{w}=1,5\right.$ e $\left.\varphi=30\right)$, (c) simulação $3(\mathrm{C} / \mathrm{z}=2$, $\rho_{s} / \rho_{w}=2$ e $\left.\varphi=30\right)$ e (d) simulação $4\left(\mathrm{C} / \mathrm{z}=4, \rho_{s} / \rho_{w}=2\right.$ e $\left.\varphi=30\right)$. 


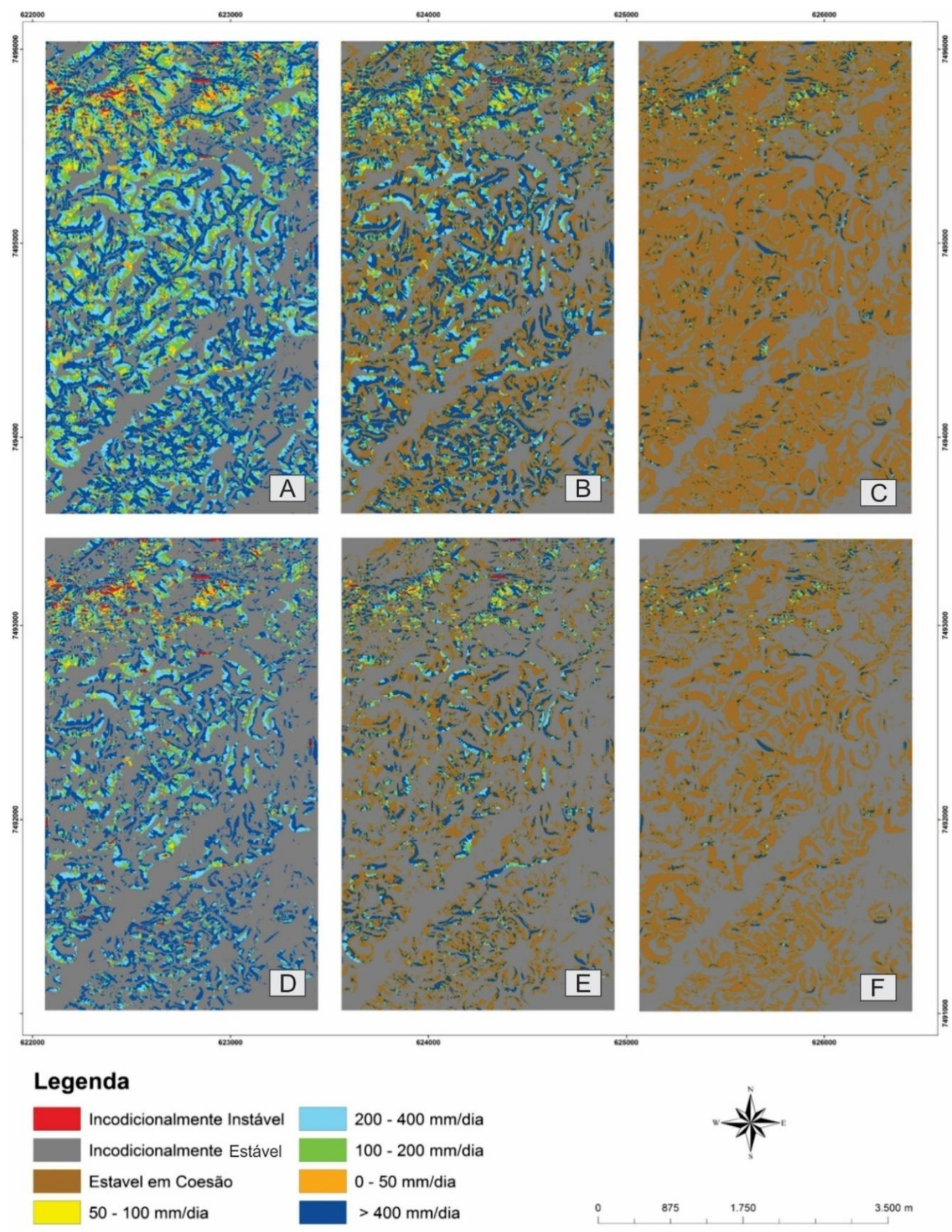

Figura 17 - Simulações do SHALSTAB utilizando os dados do MDS: (a) simulação 5), (C/z = $0, \rho_{s} / \rho_{w}=1,5$ e $\left.\varphi=45\right)$ (b) simulação $6\left(\mathrm{C} / \mathrm{z}=2, \rho_{s} / \rho_{w}=1,5\right.$ e $\left.\varphi=45\right)$, (c) simulação $7(\mathrm{C} / \mathrm{z}=$ 4, $\rho_{s} / \rho_{w}=1,5$ e $\left.\varphi=45\right)$, (d) simulação $8,\left(C / z=0, \rho_{s} / \rho_{w}=2\right.$ e $\left.\varphi=45\right)$ (e) simulação $9(\mathrm{C} / \mathrm{z}=2$, $\rho_{s} / \rho_{w}=2$ e $\left.\varphi=45\right)$, (f) simulação $10,\left(\mathrm{C} / \mathrm{z}=4, \rho_{s} / \rho_{w}=2\right.$ e $\left.\varphi=45\right)$. 


\section{3 - Resultados das Simulações com o SHALSTAB para o MDT}

As Tabelas 4 e 5 listam o número de pixels e de porcentagem das classes do SHALSTAB, considerando os diferentes valores dos atributos reológicos para o MDT. Como verificado para o MDS as condições de instabilidades aumentam com a diminuição da coesão, densidade e ângulo de atrito.

Tabela 4 - O número de pixel das classes do modelo SHALSTAB usando os dados do MDT dentro das cicatrizes, considerando os diferentes parâmetros reológicos.

\begin{tabular}{|c|c|c|c|c|c|c|c|c|c|c|c|c|}
\hline \multirow[b]{3}{*}{ CLASSES } & \multicolumn{6}{|c|}{ ÂNGULO DE ATRITO - 45} & \multicolumn{6}{|c|}{ ÂNGULO DE ATRITO - 30} \\
\hline & \multicolumn{3}{|c|}{ DENSIDADE - 2} & \multicolumn{3}{|c|}{ DENSIDADE - 1,5 } & \multicolumn{3}{|c|}{ DENSIDADE - 2} & \multicolumn{3}{|c|}{ DENSIDADE - 1,5 } \\
\hline & $\begin{array}{c}\text { COESÃo } \\
0\end{array}$ & $\begin{array}{c}\text { COESÃO } \\
2\end{array}$ & $\begin{array}{c}\text { COESÃo } \\
4\end{array}$ & $\begin{array}{c}\text { COESÃo } \\
0\end{array}$ & $\begin{array}{c}\operatorname{COES} \tilde{A} \\
02\end{array}$ & $\begin{array}{c}\text { COESẼ } \\
04\end{array}$ & $\begin{array}{c}\text { COESÃ } \\
00\end{array}$ & $\begin{array}{c}\text { COESÃ } \\
02\end{array}$ & $\begin{array}{l}\text { COESÃ } \\
\text { O } 4\end{array}$ & $\begin{array}{c}\text { COESĨ } \\
0.0\end{array}$ & $\begin{array}{c}\text { COESÃ } \\
02\end{array}$ & $\begin{array}{c}\text { COESÃ } \\
04\end{array}$ \\
\hline Instável & 27 & 3 & & 27 & 1 & & 27 & 396 & 29 & 27 & 202 & 2 \\
\hline $0-50 \mathrm{~mm} / \mathrm{dia}$ & 47 & 4 & & 115 & 26 & 1 & 47 & 254 & 30 & 115 & 249 & 12 \\
\hline 50 - 100 mm/dia & 128 & 14 & 1 & 287 & 46 & 1 & 128 & 424 & 115 & 287 & 380 & 36 \\
\hline $100-200 \mathrm{~mm} / \mathrm{dia}$ & 317 & 100 & 6 & 627 & 287 & 10 & 317 & 648 & 260 & 627 & 951 & 296 \\
\hline $200-400 \mathrm{~mm} / \mathrm{dia}$ & 915 & 323 & 75 & 1588 & 807 & 154 & 915 & 922 & 680 & 1588 & 1276 & 665 \\
\hline$>400 \mathrm{~mm} / \mathrm{dia}$ & 1164 & 598 & 42 & 1927 & 1391 & 122 & 1164 & 1126 & 828 & 1927 & 1388 & 1051 \\
\hline Estável & 3762 & 3762 & 3762 & 1789 & 1789 & 1789 & 3762 & 1363 & 1363 & 1789 & 718 & 718 \\
\hline $\begin{array}{c}\text { Estável para esta } \\
\text { coesão }\end{array}$ & & 1556 & 2474 & & 2013 & 4283 & & 1227 & 3055 & & 1196 & 3580 \\
\hline TOTAL & 6360 & 6360 & 6360 & 6360 & 6360 & 6360 & 6360 & 6360 & 6360 & 6360 & 6360 & 6360 \\
\hline
\end{tabular}

Tabela 5 - O número de pixel das classes do modelo SHALSTAB usando os dados do MDT dentro das cicatrizes, considerando os diferentes parâmetros reológicos.

\begin{tabular}{|c|c|c|c|c|c|c|c|c|c|c|c|c|}
\hline \multirow[b]{3}{*}{ CLASSES } & \multicolumn{6}{|c|}{ ÂNGULO DE ATRITO - 45} & \multicolumn{6}{|c|}{ ÂNGULO DE ATRITO - 30} \\
\hline & \multicolumn{3}{|c|}{ DENSIDADE - 2} & \multicolumn{3}{|c|}{ DENSIDADE - 1,5 } & \multicolumn{3}{|c|}{ DENSIDADE - 2} & \multicolumn{3}{|c|}{ DENSIDADE - 1,5 } \\
\hline & MDT & MDT & MDT & MDT & MDT & MDT & MDT & MDT & MDT & MDT & MDT & MDT \\
\hline Instável & 0,42 & 0,05 & 0,00 & 0,42 & 0,02 & 0,00 & 0,42 & 6,23 & 0,46 & 0,42 & 3,18 & 0,03 \\
\hline $0-50 \mathrm{~mm} / \mathrm{dia}$ & 0,74 & 0,06 & 0,00 & 1,81 & 0,41 & 0,02 & 0,74 & 3,99 & 0,47 & 1,81 & 3,92 & 0,19 \\
\hline $50-100 \mathrm{~mm} / \mathrm{dia}$ & 2,01 & 0,22 & 0,02 & 4,51 & 0,72 & 0,02 & 2,01 & 6,67 & 1,81 & 4,51 & 5,97 & 0,57 \\
\hline $100-200 \mathrm{~mm} / \mathrm{dia}$ & 4,98 & 1,57 & 0,09 & 9,86 & 4,51 & 0,16 & 4,98 & 10,19 & 4,09 & 9,86 & 14,95 & 4,65 \\
\hline $200-400 \mathrm{~mm} / \mathrm{dia}$ & 14,39 & 5,08 & 1,18 & 24,97 & 12,69 & 2,42 & 14,39 & 14,50 & 10,69 & 24,97 & 20,06 & 10,46 \\
\hline$>400 \mathrm{~mm} / \mathrm{dia}$ & 18,30 & 9,40 & 0,66 & 30,30 & 21,87 & 1,92 & 18,30 & 17,70 & 13,02 & 30,30 & 21,82 & 16,53 \\
\hline Estável & 59,15 & 59,15 & 59,15 & 28,13 & 28,13 & 28,13 & 59,15 & 21,43 & 21,43 & 28,13 & 11,29 & 11,29 \\
\hline Estável para esta coesão & 0,00 & 24,47 & 38,90 & 0,00 & 31,65 & 67,34 & 0,00 & 19,29 & 48,03 & 0,00 & 18,81 & 56,29 \\
\hline TOTAL & 100 & 100 & 100 & 100 & 100 & 100 & 100 & 100 & 100 & 100 & 100 & 100 \\
\hline
\end{tabular}


A Tabela 6 apresenta os valores referentes à média e mediana das classes de instabilidade dentro das cicatrizes digitalizadas na área de estudo, observa-se que os valore do MDS tendem a serem maiores que o MDT devido a presença de ruídos.

Tabela 6 - Valores de média e mediana dentro das cicatrizes.

\begin{tabular}{|c|c|c|c|c|c|c|}
\hline & & & Média & Média & Mediana & Mediana \\
\hline & & & MDS & MDT & MDS & MDT \\
\hline \multirow{6}{*}{ 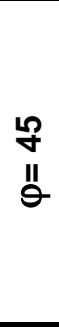 } & \multirow{3}{*}{$\begin{array}{l}N \\
11 \\
3 \\
\frac{a}{0} \\
0\end{array}$} & $\mathrm{C} / \mathrm{z}=0$ & 5 & 4 & 5 & 4 \\
\hline & & $C / z=2$ & 6 & 5 & 6 & 6 \\
\hline & & $\mathrm{C} / \mathrm{z}=4$ & 7 & 7 & 8 & 8 \\
\hline & \multirow{3}{*}{$\begin{array}{l}10 \\
11 \\
11 \\
\frac{3}{2} \\
0 \\
0\end{array}$} & $\mathrm{C} / \mathrm{z}=0$ & 4 & 3 & 4 & 3 \\
\hline & & $\mathrm{C} / \mathrm{z}=2$ & 5 & 5 & 5 & 5 \\
\hline & & $\mathrm{C} / \mathrm{z}=4$ & 7 & 6 & 8 & 6 \\
\hline \multirow{4}{*}{$\begin{array}{l}\text { 尺 } \\
\text { II }\end{array}$} & \multirow{2}{*}{$\frac{e_{0}^{3} N}{a_{0}^{\infty}}$} & $\mathrm{C} / \mathrm{z}=2$ & 3 & 2 & 3 & 1 \\
\hline & & $\mathrm{C} / \mathrm{z}=4$ & 5 & 4 & 5 & 4 \\
\hline & \multirow{2}{*}{ 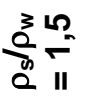 } & $\mathrm{C} / \mathrm{z}=2$ & 3 & 2 & 3 & 2 \\
\hline & & $\mathrm{C} / \mathrm{z}=4$ & 5 & 5 & 6 & 5 \\
\hline
\end{tabular}

As simulações do SHALSTAB provenientes do MDT em comparação aos do MDS apresentaram uma tendência de diminuição do número de pixel das classes de maior instabilidade. Assim, a ausência de artefatos no MDT gerou menos pixels nas classes instáveis no modelo SHALSTAB. A eliminação desses ruídos proporcionou a geração de mapas de suscetibilidade a escorregamentos mais consistente tanto numericamente como visualmente. As Figuras 18 e 19 apresentam os mapas das simulações do SHALTAB com base no MDT e nos diferentes valores dos parâmetros reológicos testados. A utilização do MDT ao invés do MDS proporcionou uma nítida melhora das simulações, onde as classes apresentam uma configuração espacial mais condizente ao relevo, acompanhando os padrões das encostas e rede de drenagens. Como verificado para o MDS as condições de instabilidades aumentaram com a diminuição da coesão, densidade e ângulo de atrito. Portanto, a simulação1 $\left(\mathrm{C} / \mathrm{z}=2, \rho_{s} / \rho_{w}=1,5\right.$ e $\left.\varphi=30\right)$ foi que apresentou as mais extensas áreas instáveis (Figura 16). Em contraposição, a simulação com maior porcentagem de áreas estáveis é a simulação $10\left(\mathrm{C} / \mathrm{z}=4, \rho_{s} / \rho_{w}=2\right.$ e $\left.\varphi=45\right)$ (Figura 17). Entre esses dois extremos é possível observar os comportamentos intermediários com relação à porcentagem de áreas estáveis e instáveis. 


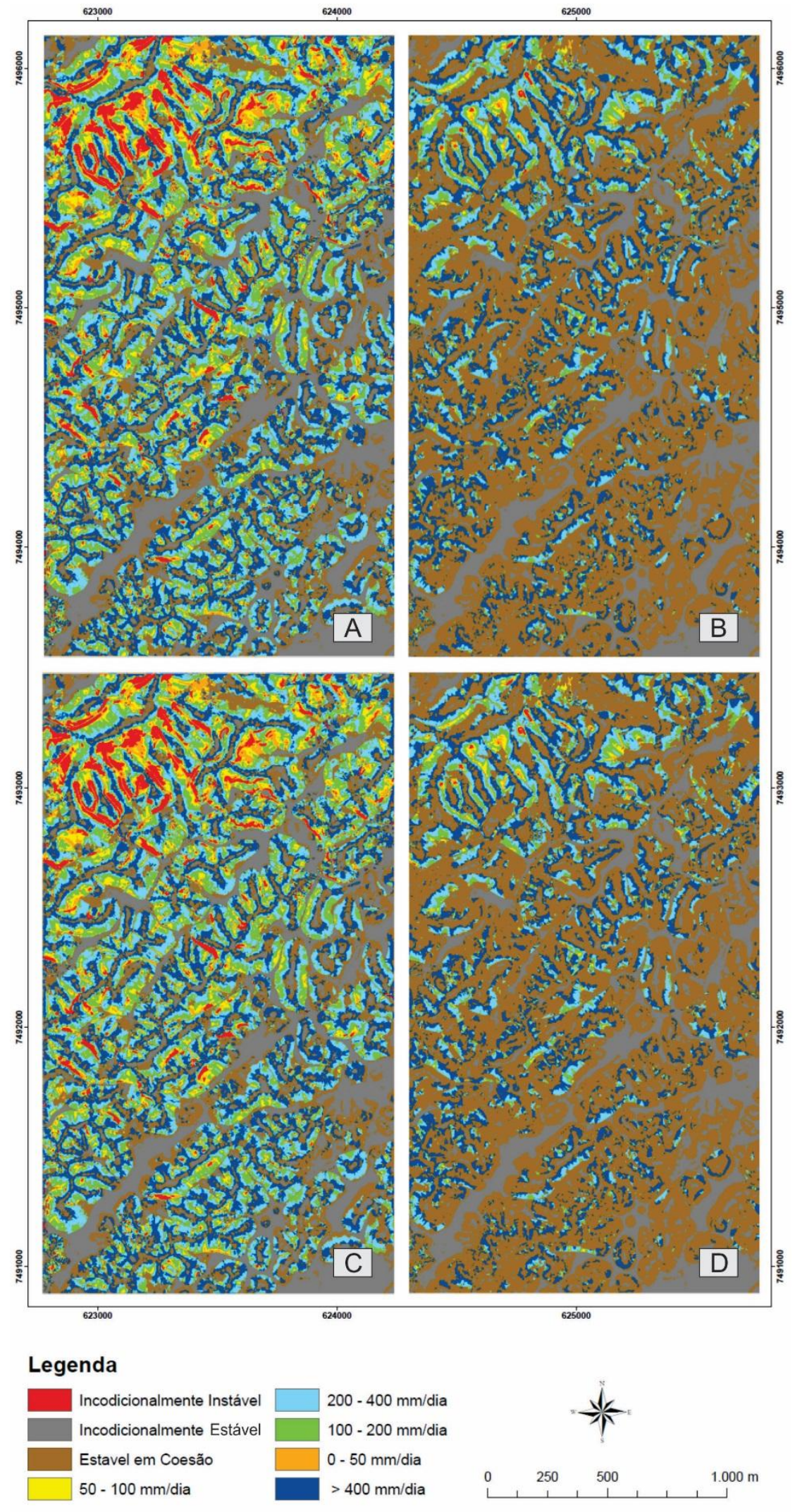

Figura 18 - Simulações do SHALSTAB utilizando os dados do MDT: (a) simulação 1 (C/z = 2, $\rho_{s} / \rho_{w}=1,5$ e $\left.\varphi=30\right)$, (b)simulação $2\left(\mathrm{C} / \mathrm{z}=4, \rho_{s} / \rho_{w}=1,5\right.$ e $\left.\varphi=30\right)$, (c) simulação $3(\mathrm{C} / \mathrm{z}=2$, $\rho_{s} / \rho_{w}=2$ e $\left.\varphi=30\right)$ e $(\mathrm{d})$ simulação $4\left(\mathrm{C} / \mathrm{z}=4, \rho_{s} / \rho_{w}=2\right.$ e $\left.\varphi=30\right)$. 


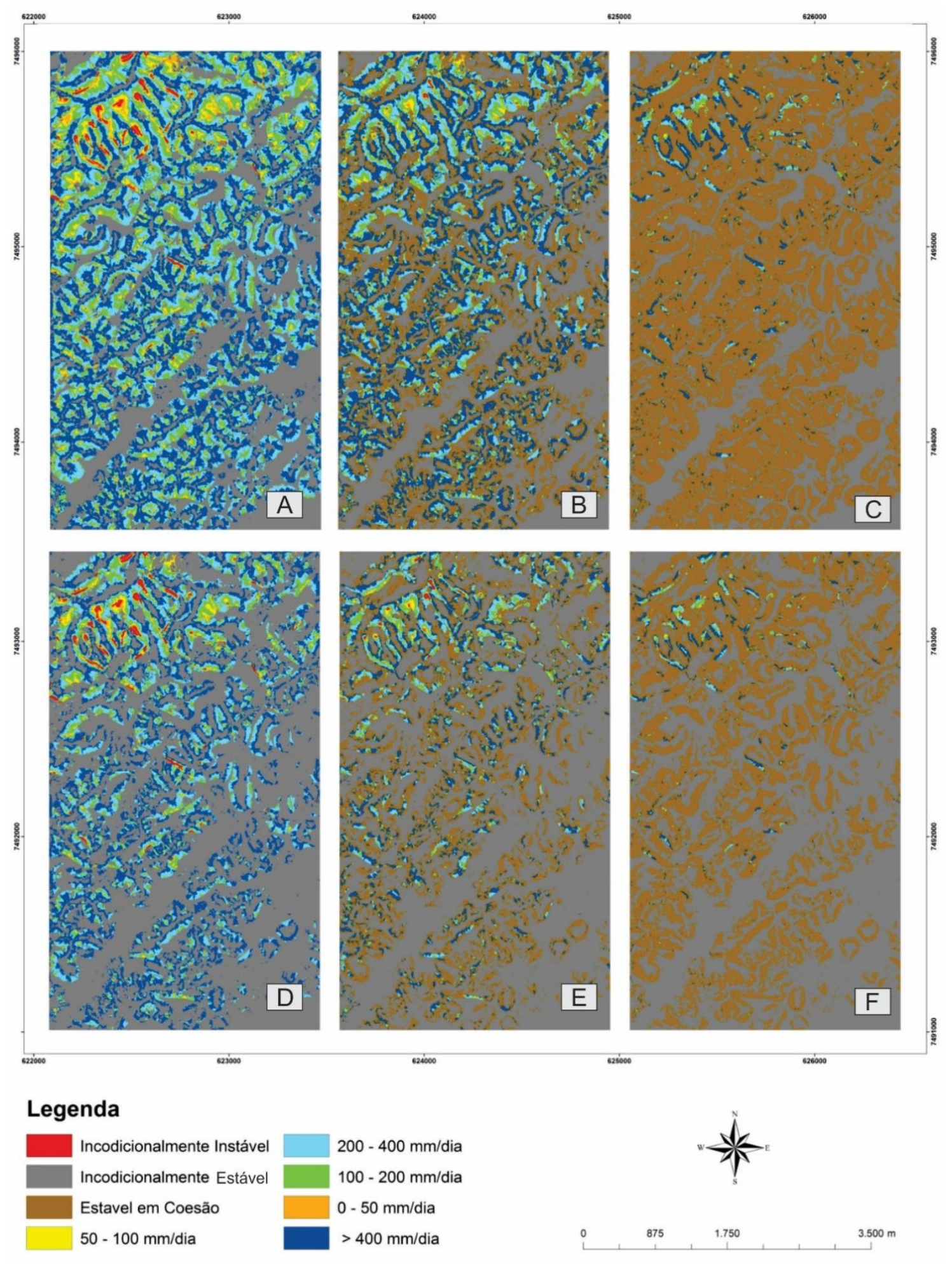

Figura 19 - Simulações do SHALSTAB utilizando os dados do MDT: (a) simulação 5$),(\mathrm{C} / \mathrm{z}=$ $0, \rho_{s} / \rho_{w}=1,5$ e $\left.\varphi=45\right)$ (b) simulação $6\left(\mathrm{C} / \mathrm{z}=2, \rho_{s} / \rho_{w}=1,5\right.$ e $\left.\varphi=45\right)$, (c) simulação $7(\mathrm{C} / \mathrm{z}=$ 4, $\rho_{s} / \rho_{w}=1,5$ e $\left.\varphi=45\right)$, (d) simulação $8,\left(\mathrm{C} / \mathrm{z}=0, \rho_{s} / \rho_{w}=2\right.$ e $\left.\varphi=45\right)$ (e) simulação $9(\mathrm{C} / \mathrm{z}=2$, $\rho_{s} / \rho_{w}=2$ e $\left.\varphi=45\right)$, (f) simulação $10,\left(\mathrm{C} / \mathrm{z}=4, \rho_{s} / \rho_{w}=2\right.$ e $\left.\varphi=45\right)$. 
O ordenamento das simulações considerando o índice de exatidão global permitiu verificar o modelo de melhor ajuste para a área de estudo. Desta forma, os parâmetros reológicos foram obtidos comparativamente com um modelo real em vez de serem obtidos por medições diretas do material. A Tabela 7 demonstra o ranque entre os dez modelos analisados. O melhor resultado foi a simulação que considerou os seguintes valores para os parâmetros reológicos $\mathrm{C} / \mathrm{z}=2, \rho_{s} / \rho_{w}=2$ e $\varphi=45$. Este resultado está condizente com 0 estudo realizado por Guimarães et al (2003) que obtiveram o mesmo modelo como o de melhor ajuste. Esse melhor modelo se caracteriza por ter um alto valor de $\varphi$, valor intermediário para baixo de $\mathrm{C} /$ ze $\rho_{s} / \rho_{w}$.

Tabela 7 - Ordenamento do ranque das simulações do SHALSTAB considerando diferentes valores para os parâmetros reológicos.

\begin{tabular}{|c|c|c|}
\hline 1 & $\mathrm{C} / \mathrm{z}=2, \rho_{s} / \rho_{w}=2$ e $\varphi=45$ & 89,42 \\
\hline 2 & $\mathrm{C} / \mathrm{z}=4, \rho_{s} / \rho_{w}=1,5$ e $\varphi=30$ & 89,39 \\
\hline 3 & $\mathrm{C} / \mathrm{z}=2, \rho_{s} / \rho_{w}=2$ e $\varphi=45$ & 89,38 \\
\hline 4 & $\mathrm{C} / \mathrm{z}=4, \rho_{s} / \rho_{w}=2$ e $\varphi=45$ & 89,19 \\
\hline 5 & $\mathrm{C} / \mathrm{z}=4, \rho_{s} / \rho_{w}=1,5$ e $\varphi=45$ & 89,12 \\
\hline 6 & $\mathrm{C} / \mathrm{z}=0, \rho_{s} / \rho_{w}=2$ e $\varphi=45$ & 88,52 \\
\hline 7 & $\mathrm{C} / \mathrm{z}=0, \rho_{s} / \rho_{w}=1,5$ e $\varphi=45$ & 88,51 \\
\hline 8 & $\mathrm{C} / \mathrm{z}=4, \rho_{s} / \rho_{w}=2$ e $\varphi=30$ & 88,31 \\
\hline 9 & $\mathrm{C} / \mathrm{z}=2, \rho_{s} / \rho_{w}=1,5$ e $\varphi=30$ & 84,07 \\
\hline 10 & $\mathrm{C} / \mathrm{z}=2, \rho_{s} / \rho_{w}=2$ e $\varphi=30$ & 78,86 \\
\hline
\end{tabular}




\section{5 - CONCLUSÃO}

No Brasil, os escorregamentos que ocorrem principalmente no período das chuvas causam grandes transtornos às comunidades atingidas devido às perdas matérias e humanas. Esse tipo de evento natural tem ocorrido em várias cidades, principalmente nas capitais onde a ocupação desordenada e acelerada avança cada vez mais em terrenos desfavoráveis à ocupação. Estudos de desastres naturais buscam subsidiar ações que impeçamos prejuízos sociais e econômicos, orientando o uso adequado da terra e evitando as áreas com risco de escorregamentos. A modelagem de escorregamentos com base física,como SHALSTAB, permite orientar e identificar as áreas mais susceptíveis a esses eventos em um baixo custo financeiro.

Um dos principais atributos de entrada na modelagem de escorregamentos é o MDT. No presente trabalho foram utilizadas técnicas fotogramétricas para confecção do MDS e MDT com resolução espacial de 5 metros. O MDS teve que ser tratado utilizando técnicas de interpolação, suavização e correção hidrográfica para a obtenção de um MDT adequado para a modelagem. Diferentes artefatos foram eliminados no MDS, tais como vegetações, edificações e outros elementos acima do relevo. A restituição e a interpolação foram meios adequados para retirada dos ruídos e deformidades causados pela vegetação existente nos MDS, a retirada da vegetação foi possível mesmo em regiões com alta densidade. A declividade e a área de contribuição gerada a partir do MDS apresentam uma alta interferência de ruídos. Em contraposição, o MDT permitiu uma melhor definição do fluxo e da declividade, atributos de terreno importantes na deflagração dos escorregamentos.

O método de retroanálise foi realizado devido à inexistência de dados reológicos na área de estudo, comparando dez simulações do SHALSTAB com o mapa de cicatrizes. No procedimento de comparação foi proposto o emprego do índice de exatidão global, considerando as áreas de cicatrizes e as áreas circunvizinhas demarcadas por um buffer de igual dimensão em área. Os resultados demonstraram que o melhor modelo é o composto pelos parâmetros reológicos $\mathrm{C} / \mathrm{z}=2, \rho_{s} / \rho_{w}=2$ e $\varphi=45$, modelo semelhante ao obtido pelo trabalho anterior de Guimarães et al. (2003). As áreas de escorregamentos ficaram concentradas na região noroeste com predomínio de relevo montanhoso. Estudos complementares utilizando testes de laboratórios devem ser feitos futuramente para confirmar os dados obtidos pela retroanálise.

Portanto, a modelagem matemática de escorregamentos possui um alto potencial para o planejamento, prevenção e diminuição de impactos causados por escorregamentos em escala local e regional. A automatização diminui os custos e aumentam a acessibilidade 
num curto prazo para que o modelo possa ser aplicado em qualquer região do país, o que torna possível a utilização em várias escalas, inclusive em áreas menos atingidas pelo poder governamental. 


\section{REFERÊNCIAS}

AHN, S J.; SCHULTES, M. A new circular coded target for the automation of photogrammetric 3D-surface measurements.In: IV Conference on Optical 3-D Measurement Techniques, Zurique, 29 de setembro a 02 de outubro de 1997, p. 225-234.

ALMEIDA, F. F. M.; CARNEIRO, C. D. R. Origem e evolução da Serra do Mar. Brazilian Journal of Geology, v. 28, n. 2, p. 135-150, 1998.

BANKOFF, G.; FRERKS, G.; HILHORST, D. Mapping vulnerability: disasters, development and people. London: Earthscan, 2004. 256 p.

BAUM, R. L.; SAVAGE, W. Z.; GODT, J. W. TRIGRS - A Fortran program for transient rainfall infiltration and grid-based regional slope-stability analysis, Version 2.0.Washigton: U.S. Department of the Interior, U. S. Geological Survey Open-File Report 02-0424, 27, 2008.

BERTOLO, P.; WIECZOREK, G. F. Calibration of numerical models for small debris flows in Yosemite Valley, California, USA. Natural Hazards and Earth System Science., v. 5, p. 993-1001, 2005.

BEVEN, K. J.; KIRKBY, M. J. A physically based, variable contributing area model of basin hydrology. Bulletin of Hydrological Sciences, v. 24, p. 43-69, 1979.

BITAR, O. Y. Cartas de suscetibilidade a movimentos gravitacionais de massa e inundações: 1:25.000 (livro eletrônico): nota técnica explicativa. São Paulo: IPT - Instituto de Pesquisas Tecnológicas do Estado de São Paulo; Brasília, DF: CPRM - Serviço Geológico do Brasil, 2014. - (Publicação IPT; 3016), 42 p.

BLIJENBERG, H. Rolling Stones? Triggering and frequency of hillslope debris flows in the Bachelard Valley, southern French Alps. Utrecht: Utrecht University, 1998.

BORGA, M.; DALLA FONTANA, G.; DA ROS, D.; MARCHI, L. Shallow landslide hazard assessment using a physically based model and digital elevation data. Environmental Geology, v. 35, n. 2-3, p. 81-88, 1998.

CAMPBELL, J. B. Introduction to remote sensing. New York: Guilford Press, 1987.551 p.

DIETRICH, W. E.; MONTGOMERY, D. R. SHALSTAB: a digital terrain model for mapping shallow landslide potential. 1998.

DOMINGUES, E. N. Caracterização das feições erosivas e relações com o meio hidrobiofisico em áreas impactadas da Serra do Mar, na região de Cubatão (SP). São Paulo, Unesp, Geociências, V20, n.1, 2001.

DOWLING, C. A., SANTI, P. M. Debris flows and their toll on human life: a global analysis of debris-flow fatalities from 1950 to 2011. Natural hazards, v. 71, n. 1, p. 203-227, 2014.

FERNANDES, N. F.; AMARAL, C. P. Movimentos de massa: uma abordagem geológico geomorfológico. In: Guerra, A. J. T.; CUNHA, S. B. Geomorfologia e meio ambiente. 4 ed. Rio de Janeiro: Bertrand Brasil, 2003.

GERENTE, J.; LUIZ, E. L.; DAL SANTO, M. A. Utilização do SHALSTAB como ferramenta para o diagnóstico preliminar da suscetibilidade a deslizamentos rasos no baixo vale do rio Luís Alves - SC. Ambiência, v. 10, n. 10, p. 333-350, 2014 
GERSCOVICH, D. M. S. Estabilidade de taludes. São Paulo: Oficina de Textos, 2012.

GOMES, R. A. T.; GUIMARÃES, R. F.; CARVALHO JÚNIOR, O. A.; FERNANDES, N. F. Análise de um modelo de previsão de deslizamentos (SHALSTAB) em diferentes escalas cartográficas. Revista Solos e Rocha, v. 28, n. 1, p. 85-97, 2005.

GOMES, R. A. T.; GUIMARÃES, R. F.; CARVALHO JÚNIOR, O. A.; FERNANDES, N. F.; AMARAL JÚNIOR, E. V. Combining spatial models for shallow landslides and debris-flows prediction. Remote Sensing, v. 13, n. 5, p. 2219-2237, 2013.

GOMES, R. A., GUIMARAES, R. F., CARVALHO JR, O. A., FERNANDES, N. F., VARGAS JR, E. A., \& MARTINS, E. S. Identification of the affected areas by mass movement through a physically based model of landslide hazard combined with an empirical model of debris flow. Natural Hazards, v. 45, n. 2, p.197-2092008.

GUIDICINI, G.; NIEBLE, C. M. Estabilidades de taludes naturais e de escavação. São Paulo: Edgard Blucher, 1983.

GUIMARÃES, R. F. Utilização de um modelo de previsão de áreas susceptíveis à escorregamentos rasos com controle topográfico: adequação e calibração em duas bacias de drenagem. 2000. Tese (Doutorado) - Universidade Federal do Rio de Janeiro, Rio de Janeiro, 2000.

GUIMARÃES, R. F., GOMES, R. A. T., CARVALHO JÚNIOR, O. A. D., MARTINS, É. D. S., OLIVEIRA, S. N. D.; FERNANDES, N. F. Análise temporal das áreas susceptíveis a escorregamentos rasos no Parque Nacional da Serra dos Órgãos (RJ) a partir de dados pluviométricos. Revista Brasileira de Geociências, v. 39, n. 1, 190-198, 2009.

GUIMARÃES, R. F.; MONTGOMERY, D. R.; GREENBERG, H. M.; GOMES, R. A. T.; VIEIRA, B. C.; FERNANDES, N. F. Aplicação do modelo SHALSTAB para determinação de áreas de risco a escorregamentos rasos em regiões tropicais. In:Congresso Brasileiro de Geologia de Engenharia, 19. São Pedro. Anais... São Paulo: ABGE, 1999.

GUIMARÃES, R. F.; MONTGOMERY, D. R.; GREENBERG, H. M.; FERNANDES, N. F.; GOMES, R. A. T.; DE CARVALHO JÚNIOR, O. A. Parameterization of soil properties for a model of topographic controls on shallow landsliding: application to Rio de Janeiro. Engineering Geology, v. 69, n. 1, p. 99-108, 2003

GUIMARÃES, R. F.; RAMOS, V. M.; REDIVO, A. L. Application of the SHALSTAB model for mapping susceptible landslide areas in mine zone (Quadrilatero Ferrifero in southeast Brazil). In: Geoscience and Remote Sensing Symposium, IGARSS'03. Proceedings, IEEE International. IEEE, 2003, v.4, p. 2444-2446.

GUIMARÃES, R. F.; CARVALHO JUNIOR, O. A.; GOMES, R. A. T.; FERNANDES, N. F. Movimentos de Massa. In: FLORENZANO, T. (Org.) Geomorfologia: conceitos e tecnologias atuais. São Paulo: Oficina de Textos, 2008.

HANSSEN, R. F. Radar interferometry: data interpretation and error analysis. Volume 2 de Remote Sensing and Digital Image Processing. Dordrecht: Springer Netherlands. 2001. $308 \mathrm{p}$.

HIRUMA, S. T.; RICCOMINI, C.; MODENESI-GAUTTIERI, M. C. 2001. Neotectônica no Planalto de Campos do Jordão, SP. Revista Brasileira de Geociências. 
HÖHLE, J. Medium-format cameras and their use in topographic mapping. In: The XXII Congress of the International Society for Photogrammetry and Remote Sensing, 2012. p. $77-82$.

HONG, Y.; ADLER, R.; HUFFMAN, G. Evaluation of the potential of NASA multi-satellite precipitation analysis in global landslide hazard assessment. Geophysical Research Letters, v. 33, L22402, 2006.

JABOYEDOFF, M.; OPPIKOFER, T.; ABELLÁN, A.; DERRON, M. H.; LOYE, A.; METZGER, R.; PEDRAZZINI, A. Use of LIDAR in landslide investigations: a review. Natural hazards, $v$. 61, n. 1, p. 5-28, 2012.

JENNESS, J.; WYNN J. J. 2005 Cohen's kappa and classification table metrics 2.0: an ArcView 3x extension for accuracy assessment of spatially explicit models. US Geological Survey open-file report OF 2005-1363. US Geological Survey, Southwest Biological Science Center, Flagstaff, AZ.

JONES, F. O. Landslides of Rio de Janeiro and the Serra das Araras Escarpment, Brazil. Washington: United States Government, 1973. (Geological Survey Professional Paper, 697).

KIRSCHBAUM, D. B.; ADLER, R.; HONG, Y.; HILL, S.; LERNER-LAM, A. A global landslide catalog for hazard applications: method, results, and limitations. Natural Hazards, v. 52, n.3, p. 561-575, 2010.

; PETERS-LIDARD, C.; HUFFMAN, G. Global distribution of extreme precipitation and high-impact landslides in 2010 relative to previous years. Journal of Hydrometeorology, v. 13, n. 5, p. 1536-1551, 2012a.

LILLESAND, T. M.; KIEFER, R. W.; CHIPMAN, J. W. Remote sensing and image interpretation. 5.ed. Madison: Wiley, 2004.763p.

LOLLINO, P.; GIORDAN, D.; ALLASIA, P. The Montaguto earth flow: A back-analysis of the process of landslide propagation. Engineering Geology, v. 170, p. 66-79. 2014.

MACHADO, R., DEHLER, N. M. Revisão e discussão do significado tectônico de granitoides do tipo-s Neoproterozóicos no estado do Rio de Janeiro. Brazilian Journal of Geology, v. 32 , n. 4, p. 471-480, 2008.

MACHADO, R., DEMANGE, M. 1994. Classificação estrutural e tectônica dos granitóides neoproterozóicos do Cinturão Paraíba do Sul no Estado do Rio de Janeiro. Boletim IG-USP. SérieCientífica, v. 25, p. 81-96.

MADSEN, S. N.; ZEBKER, H.; MARTIN, J. Topographic mapping using radar interferometry: Processing techniques. IEEE Transactions on Geoscience and Remote Sensing, v. 31, n. 1, p. 246-256, 1993.

MCDOUGALL, S.; HUNGR, O. A model for the analysis of rapid landslide motion across three-dimensional terrain. Canadian Geotechnical Journal, v. 41, n. 6, p. 1084-1097, 2004.

MEIS, M. R. M.; SILVA, J. X. Considerações geomorfológicas a propósito dos movimentos de massa ocorridos no Rio de Janeiro. Revista Brasileira de Geografia, v. 30, p. 55$72,1968 \mathrm{a}$. 
MEIS, M. R. M.; SILVA, J. X. Mouvements de masserécents, à Rio de Janeiro: Une étude de géomorphologie dynamique. Revue de Géomorphologie Dynamique, v. 18, p. 145-152, 1968b.

MENDONCA, F. B.; DINIZ, N. C.; BAPTISTA; MELLO G. M. . Mapa de Risco de Movimentos Gravitacionais de Massa, obtido por meio de Inventário de Cicatrizes de Deslizamentos no Trecho 4 do Trem de Alta Velocidade Brasileiro. Revista Brasileira de Geologia de Engenharia e Ambiental (RBGEA), v. 2, p. 73-94, 2013.

MINISTÉRIO DA SAÚDE, SECRETARIA DE VIGILÂNCIA EM SAÚDE, DEPARTAMENTO DE VIGILÂNCIA EM SAÚDE AMBIENTAL E SAÚDE DO TRABALHADOR, GOVERNO DO BRASIL. Sala de situação para atendimento à Região Serrana do Rio de Janeiro: Ações desenvolvidas pelo Ministério da Saúde, Relatório final. Brasília, Brasil, 10 de fevereiro de 2011.

MONTGOMERY, D. R.; DIETRICH, W. E. Landscape dissection and drainage area-slope thresholds. In: KIRKBY, M. J. (Ed.). Process models and theoretical geomorphology. New York: John Wiley,1994b. p. 221-246.

MONTGOMERY, D. R.; DIETRICH, W. E. A physically-based model for the topographic control on shallow landsliding. Water Resources Research, v. 30, p. 1153-1171, 1994a.

MORENO, M. R.; NASCIMENTO, M. T.; KURTZ, B. C. Estrutura e composição florística do estrato arbóreo em duas zonas altitudinais na Mata Atlântica de encosta da região do Imbé, RJ. Acta Botanica Brasilica, v. 17, n. 3, p. 371-386, 2003.

O'LOUGHLIN, E. M. Prediction of surface saturation zones in natural catchments by topographic analysis. Water Resources Research, v. 22, n. 5, p. 794-804, 1986.

OGURA, A. T., FILHO, O. A. The Morin Debris - Flow disaster at Petropolis City, Rio de Janeiro State, Brazil. Landslide News, v. 5, p. 22-24, 1991.

PACK, R. T.; TARBOTON, D. G.; GOODWIN, C. N. Terrain stability mapping with SINMAP, technical description and users guide for version 1.00. Report Number 4114-0, Terratech Consulting Ltd., Salmon Arm, Canada, 1998.

PARISE, M. Landslide mapping techniques and their use in the assessment of the landslide hazard. Phisics and Chemistry of the Earth. Vol 26, no9, 2001.

PEDUZZI, P., CHATENOUX, B., DAO, Q. H., DE BONO, A., DEICHMANN, U., GIULIANI, G., HEROLD, C.; KALSNES, B.; KLUSER, S.; LØVHOLT, F.; LYON, B.; MASKREY, A.; MOUTON, F.; NADIM, F.; SMEBYE, H. The global risk analysis for the 2009 global assessment report on disaster risk reduction. In: International Disaster and Risk Conference IDRC, Davos 2010, 30 May, 3 June 2010, Extended Summary for the On-line Conference Proceedings 2010.

PEIXOTO, G. L.; MARTINS, S. V.; SILVA, A. F.; SILVA, E. Composição florística do componente arbóreo de um trecho de Floresta Atlântica na Área de Proteção Ambiental da Serra da Capoeira Grande, Rio de Janeiro, RJ, Brasil. Acta Botanica Brasilica, v. 18, n. 1, 151-160, 2004.

PETLEY, D. Global patterns of loss of life from landslides. Geology, v. 40, n. 10, p. 927-930, 2012. 
PIRULLI, M.; COLOMBO, A.; SCAVIA, C. From back-analysis to run-out prediction: a case study in the Western Italian Alps. Landslides, v. 8, n. 2, p. 159-170, 2011

PIRULLI, M., MANGENEY, A. Results of back-analysis of the propagation of rock avalanches as a function of the assumed rheology. Rock Mechanics and Rock Engineering, v. 41, n. 1, p. 59-84, 2008.

PIRULLI, M.; SORBINO, G Assessing potential debris flow run-out: a comparison of two simulation models. Natural Hazards and Earth System Science, v. 8, p. 961-9712008

QUINN, P.; BEVEN, K.; CHEVALLIER, P.; PLANCHON, O. The Prediction of hillslope flow paths for distributed hydrological modeling using digital terrain models. Hydrological Processes, v. 5, p. 59-80, 1991.

RAMOS, V. M.; GUIMARÃES, R. F.; CARVALHO JUNIOR, O. A.; REDIVO, A. L.; GOMES, R. A. T.; CARDOSO, F. B. F.; FERNANDES, N. F. Algorithm Development for Incorporating Soil Physical Properties of each Different Soil Class in a Landslide Prediction Model (SHALSTAB). Soils \& Rocks, v. 30, p. 139-148, 2007.

RAMOS, V. M.; GUIMARÃES, R. F.; REDIVO A. L.; GOMES, R. A. T.; FERNANDES, N. F.; CARVALHO JÚNIOR, O. A.Aplicação do Modelo SHALSTAB, em Ambiente ArcView, para o mapeamento de áreas susceptíveis a escorregamento raso na Região do Quadrilátero Ferrífero (MG). Espaço \& Geografia, v. 5, n. 1, p. 49-67, 2002.

ROSS, J. L. S. Geografia do Brasil. São Paulo: EdUSP, 1996.

ROSSI, G.; CATANI, F.; LEONI, S.; SEGONI, S.; TOFANI, V. HIRESSS: a physically based slope stability simulator for HPC applications. Natural Hazards and Earth System Science, v. 13, n. 1, p. 151-166, 2013.

ROTTENSTEINER, F.; SOHN, G.; JUNG, J.; GERKE, M.; Baillard, C.; BENITEZ, S.; BREITKOPF, U. The ISPRS benchmark on urban object classification and 3D building reconstruction. ISPRS Ann. Photogramm. Remote Sens. Spatial Inf. Sci., v. 1, n. 3, p. 293-298, 2012.

SANTI, P.M.; HEWITT, K.; VANDINE, D.F.; BARILLAS, E. M. Debris-flow impact, vulnerability, and response. Natural Hazards, v. 56, n. 1, p. 371-402, 2010.

SELBY, M. J. Hillslope materials and processes. New York: Oxford University Press, 1993.

SILVA, E. L.; GOMES, R. A. T; GUIMARÃES, R. F.; CARVALHO JÚNIOR, O. A. Emprego de modelo de susceptibilidade a escorregamentos rasos para gestão de riscos de desastres no município de Vitória-ES. Sociedade \& Natureza, v. 25, p. 119-132, 2013.

SLAYMAKER, O. Assessment of the geomorphic impacts in British Columbia. Ambio: A Journal of the Human Environment, v. 29, n. 7, p. 381-387, 2000.

SPREAFICO M. C.; FRANCIONI, M.; CERVI. F.; STEAD, D.; BITELLI, G.; GHIROTTI. M.; GIRELLI, V. A.; LUCENTE, C. C.; TINI, M. A.; BORGATTI, L. Back Analysis of the 2014 San Leo Landslide Using Combined Terrestrial Laser Scanning and 3D Distinct Element Modelling. Rock Mechanics and Rock Engineering, p. 1-17, 2015.

STORY, M.; CONGALTON, R. G. Accuracy assessment - A user's perspective. Photogrammetric Engineering and Remote Sensing, v. 52, n. 3, p. 397-399, 1986. 
TABARELLI, M.; MANTOVANI, W. 1999a. Clareirasnaturais e a riqueza de espécies pioneiras em umafloresta Atlântica montana. Revista Brasileira de Biologia, v. 59, n. 2,p. 251-261

TO, T.; NGUYEN, D.; TRAN, G. Automated 3d architecture reconstruction from photogrametric structure and motion: a case study of the "one pilla" pagoda, hanoi, Vietnam.The International Archives of the Photogrammetry, Remote Sensing and Spatial Information Sciences, v. XL-7/W3, 2015.

VIEIRA, B. C.; RAMOS, H. Aplicação do modelo SHALSTAB para mapeamento da suscetibilidade a escorregamentos rasos em Caraguatatuba, Serra do Mar (SP). Revista do Departamento de Geografia, v. 29, p. 161-174, 2015.

VIVIANI, E.; MANZATO, G. G. Geração de modelos digitais de superfície por meio de plataformas computacionais com estrutura vetorial e raster. Ciência \& Engenharia, v. 15, n. 2, p. 27-34, 2005.

WEHR, A.; LOHR, U. Airborne laser scanning-an introduction and overview. ISPRS Journal of Photogrammetry and Remote Sensing, v. 54, n. 2, p. 68-82, 1999.

WU, W.; SIDLE, R. C.A distributed slope stability model for steep forested basins. Water Resources Research, v. 31, p. 2097-2110, ago. 1995.

ZAIDAN, R. T.; FERNANDES, N. F. Zoneamento de susceptibilidade a escorregamentos em encostas aplicado à bacia de drenagem urbana do córrego do Independência - Juiz de Fora (MG). Revista Brasileira de Geomorfologia, v. 10, n. 2, p. 57-76, 2009. 